\title{
River runoff influences on the Central Mediterranean overturning circulation
}

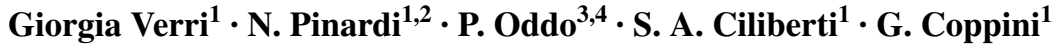

Received: 15 June 2016 / Accepted: 28 April 2017 / Published online: 23 May 2017

(C) The Author(s) 2017. This article is an open access publication

\begin{abstract}
The role of riverine freshwater inflow on the Central Mediterranean Overturning Circulation (CMOC) was studied using a high-resolution ocean model with a complete distribution of rivers in the Adriatic and Ionian catchment areas. The impact of river runoff on the Adriatic and Ionian Sea basins was assessed by a twin experiment, with and without runoff, from 1999 to 2012. This study tries to show the connection between the Adriatic as a marginal sea containing the downwelling branch of the anti-estuarine CMOC and the large runoff occurring there. It is found that the multiannual CMOC is a persistent anti-estuarine structure with secondary estuarine cells that strengthen in years of large realistic river runoff. The CMOC is demonstrated to be controlled by wind forcing at least as much as by buoyancy fluxes. It is found that river runoff affects the CMOC strength, enhancing the amplitude of the secondary estuarine cells and reducing the intensity of the dominant anti-estuarine cell. A large river runoff can produce a positive buoyancy flux without switching off the antiestuarine CMOC cell, but a particularly low heat flux and wind work with normal river runoff can reverse it. Overall by comparing experiments with, without and with unrealistically augmented runoff we demonstrate that rivers affect the CMOC strength but they can never represent its
\end{abstract}

Giorgia Verri

giorgia.verri@cmcc.it

1 Centro EuroMediterraneo sui Cambiamenti Climatici, Via A. Imperatore 16, 73100 Lecce, Italy

2 Universita' degli Studi di Bologna, Dipartimento di Fisica e Astronomia, Bologna, Italy

3 Istituto Nazionale di Geofisica e Vulcanologia, Bologna, Italy

4 Present Address: Center for Maritime Research and Experimentation CMRE, La Spezia, Italy dominant forcing mechanism and the potential role of river runoff has to be considered jointly with wind work and heat flux, as they largely contribute to the energy budget of the basin. Looking at the downwelling branch of the CMOC in the Adriatic basin, rivers are demonstrated to locally reduce the volume of Adriatic dense water formed in the Southern Adriatic Sea as a result of increased water stratification. The spreading of the Adriatic dense water into the Ionian abyss is affected as well: dense waters overflowing the Otranto Strait are less dense in a realistic runoff regime, with respect to no runoff experiment, and confined to a narrower band against the Italian shelf with less lateral spreading toward the Ionian Sea center.

\section{Introduction}

The annual mean freshwater budget in the Mediterranean Sea, composed of evaporation minus precipitation and river runoff, has been found to be positive, corresponding to a net surface loss of $0.54 \pm 0.15 \mathrm{~m} /$ year as the average of several long term annual estimates proposed by SanchezGomez et al. (2011). Moreover, the net heat budget of the basin is well known to be negative according to most estimates (Bethoux 1979; Pettenuzzo et al. 2010; SanchezGomez et al. 2011; Schroeder et al. 2012). The combination of the positive freshwater budget and the negative heat budget of the Mediterranean Sea gives a net buoyancy loss, thus sustaining a vigorous mean kinetic energy in the basin (Cessi et al. 2014).

This forcing induces also a vigorous meridional antiestuarine overturning circulation. Pickard and Emery (1982) differentiate between the semienclosed seas with horizontally and vertically separated inflow and outflow regimes at the strait. Semienclosed basins with strait flows that 
are vertically separated can have two vertical circulation modes, estuarine and antiestuarine.

Traditionally, the estuarine and anti-estuarine circulation in semienclosed seas has been classified on the basis of the surface water flux and the conservation of salt (Knudsen 1900; Sverdrup 1947; Pickard and Emery 1982). More precisely, estuarine and anti-estuarine circulations can then be represented by meridional overturning cells which form into the semi-enclosed basin and which are connected to the external regions by the Strait inflow/outflow system.

The general characteristics of the Mediterranean overturning circulation are schematized in Fig. 1 (Pinardi et al. 2006). This circulation is characterized by interannual as well as multi-decadal time scales and it is composed of three major conveyor belts: the Zonal Overturning Circulation (ZOC) in the Southern Mediterranean propelled by the Gibraltar stream flow and Levantine Intermediate Water (LIW) formation processes, the Western Mediterranean Meridional Overturning Circulation (WMOC) originating in the Gulf of Lion, the Central Mediterranean MOC originating in the Adriatic Sea (CMOC). These overturning cells are triggered by buoyancy losses and water mass sinking occurring in the regions offshore the Gulf of Lions, in the Southern Adriatic and in the Northern Levantine Basin, enhanced by the presence of large scale permanent cyclonic gyres driven by wind stress curl (Pinardi et al. 2006). The Aegean Sea is marked as another dense water site in Fig. 1: Roether et al. (1996) and Gertman et al. (2006) demonstrated that dense waters could form there during intense winters and

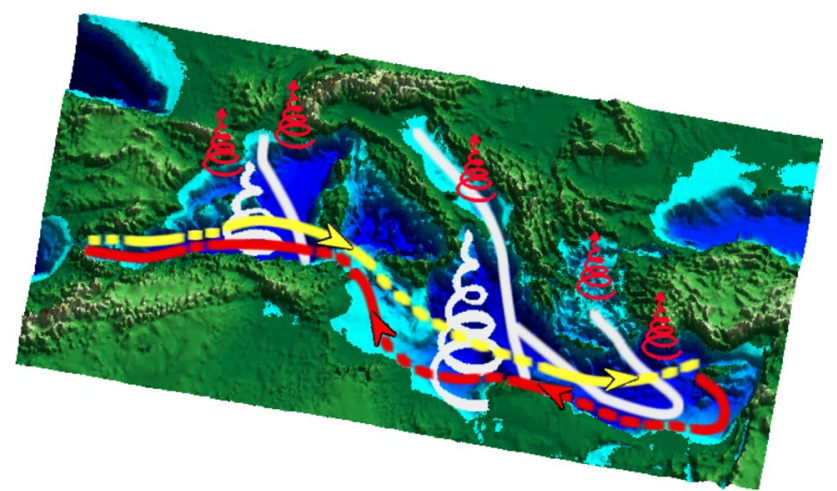

Fig. 1 The conveyor belts of the Mediterranean Sea. The red and yellow dashed streamlines in the zonal direction stand for the zonal overturning circulation in the surface-intermediate layers that is forced by the Gibraltar stream flow and Levantine Intermediate Water (LIW) formation processes. The red spirals indicate the preferential sites for strong heat losses during wintertime and dense water formation processes. Two anti-cyclonic meridional overturning circulation patterns can be distinguished (white spirals): the Western Mediterranean MOC originating in the Gulf of Lion, and the Central Mediterranean MOC originating in the Adriatic Sea. Reproduced from Pinardi et al. (2006) large LIW inflow from the Levantine basin. This Aegean Meridional Overturning Circulation (AeMOC) characterizes the Eastern Mediterranean Transient (EMT) which started at the end of the eighties and ended around the middle of the nineties. Gacic et al. (2011) pointed out that the EMT could be a repeating phenomenon, and part of its cause is connected with inversions of the Ionian circulation.

The CMOC occupies the Northern Ionian Sea and extends into the Southern Adriatic (Fig. 1). The lower branch of the CMOC is connected with the outflowing of the Southern Adriatic dense waters (Artegiani et al. 1997a; Vilibić and Orlić 2001-2002; Manca et al. 2002; Mantziafou and Lascaratos 2004, 2008; Wang et al. 2007; Bensi et al. 2013b) in the Ionian abyssal basin. Several authors discussed that, during the EMT, the Adriatic source of Ionian abyssal waters could have been replaced by the Cre$\tan$ Sea deep waters (Roether et al. 1996; Roussenov et al. 2001; Curchitser et al. 2001; Manca et al. 2003; Rubino and Hainbucher 2007; Ursella et al. 2011; Rubino et al. 2012; Bensi et al. 2013a).

In this paper we would like to exhamine for the first time the question of what is the influence of river runoff on the CMOC. The question is relevant because more than $30 \%$ of the Mediterranean runoff is concentrated in the Adriatic Sea and the hypothesis that large freshwater runoff in the Adriatic could shutdown the CMOC is realistic at least for the past. As far as we know this is the first study on the river influence on the CMOC, similar to Rahmstorf's study (Rahmstorf 1995) on the freshwater role in the Northern Atlantic overturning circulation. Previously, Skliris et al. (2007) and Vervatis et al. (2013) investigated the impact of reduced discharge of Ebro and Nile rivers on the dense water formation in the Eastern and Western Mediterranean sub-basins.

More generally, the role of freshwater inputs (due to both rivers and precipitations) on the dynamics of a marginal sea, such as the Adriatic basin, has been widely investigated in the literature. Spall (2012) demonstrates that, in marginal sea areas, an increase in surface freshwater gain can lead to a shutdown of dense water formation and sinking, and the marginal sea MOC switches from antiestuarine to estuarine mode. Recently, Cessi et al. (2014) established that the estuarine/anti-estuarine character of a semi-enclosed sea with a two-layer flow at the strait is determined by both wind and buoyancy forcings. The wind forcing is normally a source of mechanical energy for the circulation, while the buoyancy forcing could be either an energy source or a sink depending on the sign of the net buoyancy flux at the surface. For estuarine basins, such as the Baltic and Black Sea, the positive buoyancy flux (dominated by precipitation and runoff exceeding evaporation), is a net energy sink for the circulation, thus producing a less 
vigorous meridional circulation than in the anti-estuarine basins.

The Adriatic Sea is a "dilution basin" with a negative annual freshwater budget, equal to the difference between evaporation and precipitation and runoff, of about $-1 \mathrm{~m}$ year $^{-1}$ (Artegiani et al. 1997a, b) but a negative annual mean heat budget. The buoyancy flux could eventually then be positive, thus determining a net sink of energy and possibly a net estuarine character of the circulation. Pinardi et al. (2006) show that, due to river runoff, the Adriatic Sea could be characterized by zero net buoyancy flux, thus producing a basin where the circulation is mainly powered by the wind stress. However, the energetics proposed by Cessi et al. (2014) cannot be applied satisfactorily to the Adriatic Sea, since the flow at Otranto is not just a two-layer flow. Thus, a comprehensive analysis of surface buoyancy and the CMOC is needed to fully establish the estuarine/anti-estuarine character of the Adriatic Sea circulation.

In order to answer the effects of runoff on the CMOC and the Adriatic Sea deep water formation mechanisms, a high resolution general circulation model was set up, forced by realistic fluxes of water, heat and momentum. The impact of river runoff on the circulation is assessed by using a mechanistic approach: a full forcing and dynamics experiment is compared to a zero-runoff case. The full forcing experiment is considered to be the present state of the Adriatic Sea and it is validated with existing data sets.

The paper is organized as follows. Section 2 outlines the experimental design, and details the parameterization of the rivers as surface boundary conditions and the validation of the model performance. Section 3 describes the experiments highlighting the role of the river runoff forcing. A summary and conclusions are presented in the last section.

\section{Experimental design}

\subsection{Model configuration and experiments set-up}

The numerical model used is the Nucleus for European Modelling of the Ocean, NEMO (Madec 2008), that is a three-dimensional finite difference numerical model adopting the Boussinesq and hydrostatic approximations and using the linear explicit free surface formulation. The area covered by the model grid is the Central Mediterranean Sea from 12.2 to $21.0^{\circ} \mathrm{E}$ and 30.2 to $45.8^{\circ} \mathrm{N}$ with a horizontal resolution of about $2.2 \mathrm{~km}(2.5 \mathrm{~km}$ in the meridional direction and 1.7-2.2 km in the zonal direction). Figure 2 shows the bathymetry of the domain, river mouth grid points and the three sub-regions into which the Adriatic
Sea is conventionally subdivided on the basis of its bottom morphology: the Northern (NAd), the Middle (MAd) and the Southern Adriatic (SAd). The connection with the Ionian Sea occurs at the Otranto Strait where the sill is $800 \mathrm{~m}$ deep, located at approximately $40^{\circ} \mathrm{N}$.

This model is the first implementation of the NEMO code over the Central Mediterranean Sea area, with a representation of almost all the rivers flowing into the Central Mediterranean Sea. In this work the regional model is forced by a $1 / 16^{\circ}$ resolution daily analyses from the operational Mediterranean forecasting system, MFS (Tonani et al. 2008; Pinardi and Coppini 2010) at the lateral open boundaries. The numerical model configuration is explained in details in "Appendix 1".

A set of experiments were performed with present day river runoff, without river runoff and with augmented runoff (Table 1), spanning the period from 1 January 1999 to 31 December 2012. The time series of the kinetic energy integrated over the basin volume (not shown) shows that the spin up period consists of the first few months of 1999, thus this year has been eliminated from the analysis. Such short spin up is due to the fact that the model was initialized by close-to-present-day fields from MFS model.

It is worth to stress that the conceptual paradigm of this study is to explain the "theoretical role" of river inflow since the case without or with increased runoff corresponds to extreme conditions with respect to the present day. EXP1 corresponds as closely as possible to reality and this is our reference against which we analyze the effects only of river runoff changes, leaving all the other forcings identical because we know that the estuarine water balance of the Adriatic is due to river runoff.

\subsection{River runoff datasets}

River runoff into the Mediterranean Sea is mainly concentrated in the Central Mediterranean sub-basin, with rivers flowing into the Adriatic Sea providing almost 1/3 of the total runoff (Struglia et al. 2004; Ludwig et al. 2009). Overall the Mediterranean Sea counts on a great number of very small rivers (Milliman 2001), owing to strong topographic relief favouring the formation of small watersheds. The construction of dams in the Nile and Ebro have reduced their runoff in the Mediterranean (Nile from 2700 to $150 \mathrm{~m}^{3} \mathrm{~s}^{-1}$, Ebro from 1500 to $400 \mathrm{~m}^{3} \mathrm{~s}^{-1}$ ) so that currently the only major runoff sources located out of the Central Mediterranean Sea are the Rhone and the Ebro rivers flowing into the Western sub-basin.

The freshwater discharge into the Central Mediterranean Sea is almost totally concentrated along the Adriatic coastlines: the Po river is the main freshwater source of the 


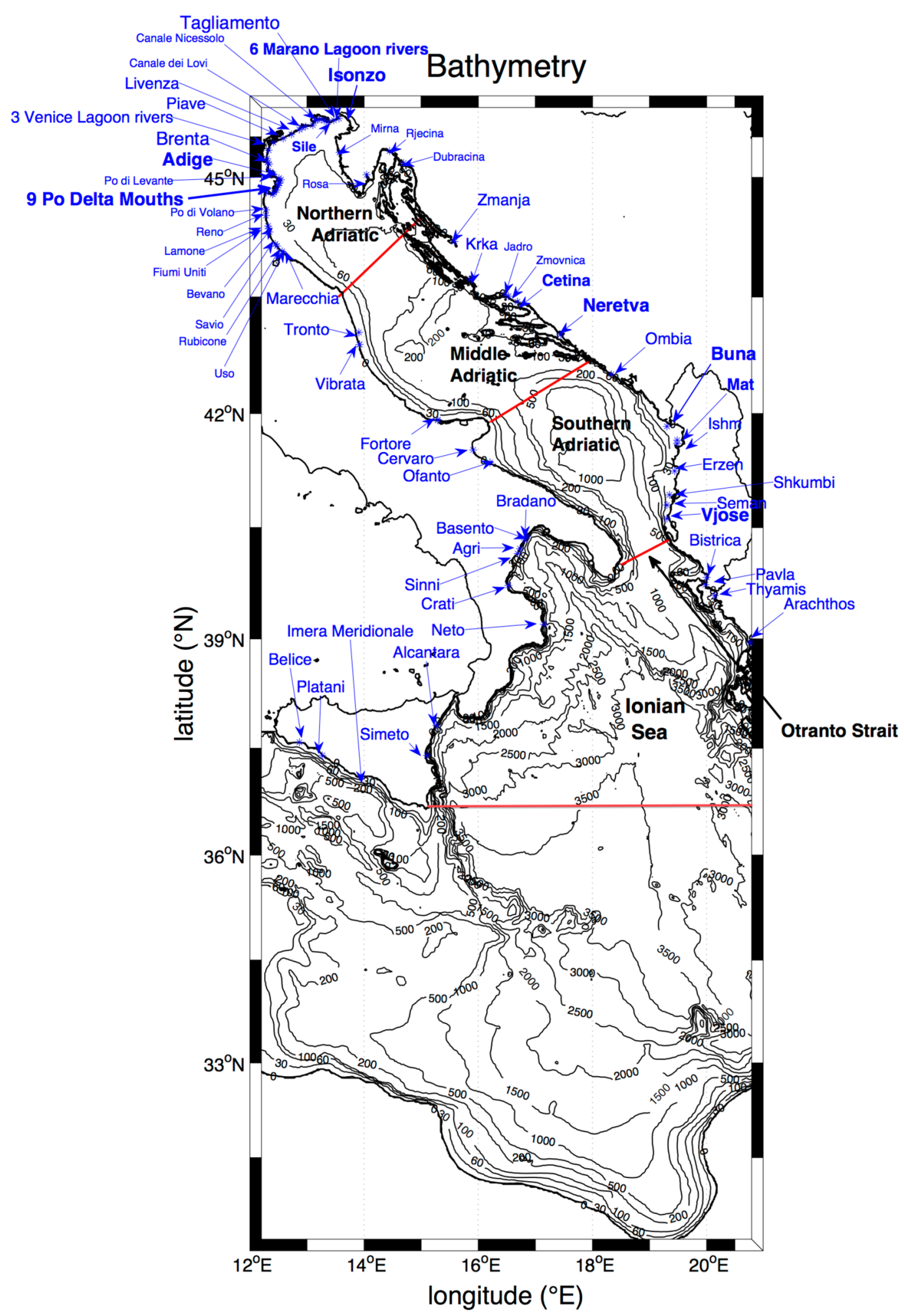

Fig. 2 Model domain and details on areas of interest. The red lines define the three Adriatic sub-regions and the Ionian Sea. Black isolines show the bathymetry. Blue stars and arrows indicate the model river mouths 
Table 1 List of experiments and the runoff values assumed

\begin{tabular}{ll}
\hline Experiment & River discharge \\
\hline EXP 1 & $\begin{array}{l}\text { Realistic river discharge: } 67 \text { surface sources of climatological runoff } \\
\text { (except daily observations for the Po river runoff) and constant } \\
\text { salinity }\end{array}$ \\
EXP 2 & No river discharge \\
EXP 3 & Mean annual discharge augmented of 50\% with respect to Exp1 \\
EXP 4 & Mean annual discharge augmented of $100 \%$ with respect to Exp1 \\
\hline
\end{tabular}

Central Mediterranean Sea and accounts for almost 30\% of the Adriatic annual discharge (Cushman-Roisin et al. 2002). Besides the Po, other significant freshwater inputs are the Buna/Bojana, Vjose and Neretva along the Eastern Adriatic coast, and the Adige and Isonzo along the northern Italian coast.

Several Mediterranean river discharge datasets have started to be collected during the last decade. Ludwig et al. (2009) proposed a reconstruction of the river runoff of the Mediterranean and Black Seas during the period 1960-2000, on the basis of available observations and empirical modeling for rivers and time periods where observations were missing. Ludwig et al. (2009) time series considers 295 Mediterranean and Black Sea rivers with the condition they cover at least 20 years as reference period. Many of the records were downloaded by Mediterranean Hydrological Cycle Observing System, Medhycos, data server (Medhycos 2001), other from the Global River Discharge database RivDis (Vörösmarty et al. 1996), or from the Hydro database at the French Ministry of Environment (Hydro 2006). Struglia et al. (2004) provides an extensive representation of historical river release into the Mediterranean basin, timeseries of 67 rivers are derived from the Global Runoff Data Center (GRDC) hydrological database and the Medhycos database.

Most of the datasets we adopted consist of observations taken at the hydrometric stations nearest to river mouths, and few of them are estimated values (Pasaric 2004; Malacic and Petelin 2009; Raicich 1996). Time series for the various rivers cover different periods. However, the time series of the major rivers, accounting for the most of the Central Mediterranean discharge, overlap at least for 20 years. The databases we considered have been provided by the GRDC, the regional agency Autorita' di Bacino Basilicata, the hydrological division of the National Research Council CNR IRPI, the regional agencies for the environmental protection ARPAs, the Albanian Hydrometeorological Institute.

Overall this study considers 67 Adriatic and Ionian rivers in total, 52 flowing into the Adriatic Sea and 15 into the Ionian Sea. Table 2 lists the adopted climatological datasets for river runoff, the time range for computing the monthly climatologies and the annual mean discharges as useful reference values.

All river mouths are "point sources" except for 2: Marecchia to Tronto rivers (Tronto excluded) in the Marche region and Vibrata to Fortore rivers (Fortore excluded) in the Abruzzo and Molise regions which are "diffused sources", i.e. the runoff was split across several grid points. These diffused sources and the rivers in Puglia are the only rivers of the model based on Raicich's (1996) climatologies (see Fig. 2 for locating river outlets).

The Po river runoff, referred to the Pontelagoscuro station, usptream of the delta, is unequally subdivided between the nine grid points representing the nine branches of the delta (Po di Goro, Po di Gnocca, Po di Tolle, Po di Bastimento, Po di Scirocco, Po di Bonifazi, Po di Dritta, Po di Tramontana, Po di Maistra) according to percentages in Provini et al. (1992).

Daily time series of total discharge in the model domain during the simulation period (1 January 1999-31 December 2012), are shown in the top panel of Fig. 3, with overlapped Po daily discharge as well as the contribution of all the other rivers (i.e. monthly climatologies interpolated on daily basis). Middle panel highlights the added value of working with daily observations of Po river instead of considering monthly climatologies. Finally the bottom panel shows how the Adriatic river release, Po river excluded, is represented by Raicich's climatologies (1996), Ludwig's climatologies (Ludwig et al. 2009) and the new climatologies we chose in this study on the basis of more updated and reliable datasets. To note that our dataset includes 52 rivers flowing into the Adriatic Sea, while Raicich (1996) considers only 45 and Ludwig et al. (2009) only 32 Adriatic rivers.

Adding all the contributions, the annual average runoff in the Central Mediterranean Sea is equal to $4.72 \times 10^{3} \mathrm{~m}^{3} \mathrm{~s}^{-1}, 29.7 \%$ coming from the Po river only, $94.6 \%$ is the contribution of all the Adriatic rivers and $5.4 \%$ the one of the Ionian rivers. Maximum values of the total discharge on daily basis were observed in autumn 2000, autumn 2002, and autumn 2008-winter 2009. Annual mean peaks took place in $2000\left(5.28 \times 10^{3} \mathrm{~m}^{3} \mathrm{~s}^{-1}\right), 2002$ 
Table 2 River runoff climatological values adopted for the Adriatic and Ionian rivers, time period for the climatologies and mean annual discharge values

\begin{tabular}{|c|c|c|c|c|}
\hline River & Dataset & Reference period & Discharge basin & $\begin{array}{l}\text { Mean annual } \\
\text { discharge } \\
\left(\mathrm{m}^{3} \mathrm{~s}^{-1}\right)\end{array}$ \\
\hline Adige (Italy) & GRDC & $1922-1984$ & Adriatic Sea & 223.75 \\
\hline Agri (Italy) & Autorita' di bacino Basilicata & n.r & Ionian Sea & 9.14 \\
\hline Alcantara (Italy) & Piano Tutela Acque Sicilia & 1980-1997 & Ionian Sea & 4.7 \\
\hline Arachthos (Greece) & GRDC & $1964-1980$ & Ionian Sea & 19.73 \\
\hline Basento (Italy) & CNR IRPI & $1933-1971$ & Ionian Sea & 13.23 \\
\hline Belice (Italy) & Piano Tutela Acque Sicilia & $1980-2000$ & Ionian Sea & 51.57 \\
\hline Bevano (Italy) & ARPA EMR & n.r & Adriatic Sea & 6 \\
\hline Bistrica (Albania) & Albanian Hydrometeorological Institute & 1949-1987 & Ionian Sea & 32.1 \\
\hline Bocca di Primero (Italy) & ARPA VENETO & n.r & Adriatic Sea & 10.28 \\
\hline Bradano (Italy) & CNR IRPI & $1929-1971$ & Ionian Sea & 5.85 \\
\hline Brenta (Italy) & ARPA VENETO & n.r & Adriatic Sea & 93.17 \\
\hline Buna/Bojana (Albania-Montenegro) & Albanian Hydrometeorological Institute & $1965-1985$ & Adriatic Sea & 675 \\
\hline Canale dei Lovi (Italy) & ARPA VENETO & n.r & Adriatic Sea & 22.7 \\
\hline Canale di Morgo (Italy) & ARPA VENETO & n.r & Adriatic Sea & 10.28 \\
\hline Canale Nicessolo (Italy) & ARPA VENETO & n.r & Adriatic Sea & 22.7 \\
\hline Cervaro (Italy) & Raicich (1996) & n.r & Adriatic Sea & 2.92 \\
\hline Cetina (Croatia) & Pasaric (2004) & $1947-2000$ & Adriatic Sea & 88.28 \\
\hline Crati (Italy) & CNR IRPI & $1926-1966$ & Ionian Sea & 26.2 \\
\hline Dubracina (Croatia) & Pasaric (2004) & $1947-2000$ & Adriatic Sea & 4.14 \\
\hline Erzen (Albania) & Albanian Hydrometeorological Institute & 1949-1992 & Adriatic Sea & 16.9 \\
\hline Fiumi Uniti (Italy) & ARPA EMR & n.r & Adriatic Sea & 12.06 \\
\hline Fortore (Italy) & Raicich (1996) & n.r & Adriatic Sea & 12.25 \\
\hline Imera Meridionale (Italy) & GRDC & $1978-1980$ & Ionian Sea & 4.26 \\
\hline Ishm (Albania) & Albanian Hydrometeorological Institute & $1968-1992$ & Adriatic Sea & 19.8 \\
\hline Isonzo (Italy) & Malacic and Petelin (2009) & $1945-2000$ & Adriatic Sea & 110.43 \\
\hline Jadro (Croatia) & Pasaric (2004) & $1947-2000$ & Adriatic Sea & 7.18 \\
\hline Krka (Croatia) & Pasaric (2004) & $1947-2000$ & Adriatic Sea & 56.51 \\
\hline La Fosa (Italy) & ARPA VENETO & n.r & Adriatic Sea & 10.28 \\
\hline Lamone (Italy) & ARPA EMR & n.r & Adriatic Sea & 12.06 \\
\hline Livenza (Italy) & ARPA VENETO & n.r & Adriatic Sea & 88.33 \\
\hline Marecchia to Tronto, Tronto excluded (Italy) & Raicich (1996) & $1956-1965$ & Adriatic Sea & 121.92 \\
\hline Mat (Albania) & Albanian Hydrometeorological Institute & $1951-1986$ & Adriatic Sea & 87.4 \\
\hline Mirna (Croatia) & Pasaric (2004) & $1947-2000$ & Adriatic Sea & 7.91 \\
\hline Neretva (Croatia) & Pasaric (2004) & $1947-2000$ & Adriatic Sea & 366.86 \\
\hline Neto (Italy) & ARPA CAL & n.r & Ionian Sea & 6.22 \\
\hline Ofanto (Italy) & Raicich (1996) & n.r & Adriatic Sea & 14.92 \\
\hline Ombla (Croatia) & Pasaric (2004) & $1947-2000$ & Adriatic Sea & 27 \\
\hline Pavla (Albania) & Albanian Hydrometeorological Institute & $1951-1991$ & Ionian Sea & 6.69 \\
\hline Piave (Italy) & ARPA VENETO & n.r & Adriatic Sea & 54.33 \\
\hline Platani (Italy) & GRDC & $1978-1980$ & Ionian Sea & 2.37 \\
\hline Po di Levante (Italy) & ARPA EMR & n.r & Adriatic Sea & 21.67 \\
\hline Po di Volano (Italy) & ARPA EMR & n.r & Adriatic Sea & 6 \\
\hline Pto Buso (Italy) & ARPA VENETO & n.r & Adriatic Sea & 10.28 \\
\hline Pto di Chioggia (Italy) & ARPA VENETO & n.r & Adriatic Sea & 17.27 \\
\hline Pto di Lido (Italy) & ARPA VENETO & n.r & Adriatic Sea & 17.27 \\
\hline Pto di Malamocco (Italy) & ARPA VENETO & n.r & Adriatic Sea & 17.27 \\
\hline Pto Lignano (Italy) & ARPA VENETO & n.r & Adriatic Sea & 10.28 \\
\hline
\end{tabular}


Table 2 (continued)

\begin{tabular}{|c|c|c|c|c|}
\hline River & Dataset & Reference period & Discharge basin & $\begin{array}{l}\text { Mean annual } \\
\text { discharge } \\
\left(\mathrm{m}^{3} \mathrm{~s}^{-1}\right)\end{array}$ \\
\hline Rasa (Croatia) & Pasaric (2004) & $1947-2000$ & Adriatic Sea & 1.58 \\
\hline Reno (Italy) & ARPA EMR & n.r & Adriatic Sea & 49.33 \\
\hline Rjecina (Croatia) & Pasaric (2004) & $1947-2000$ & Adriatic Sea & 7.22 \\
\hline Rubicone (Italy) & ARPA EMR & n.r & Adriatic Sea & 6 \\
\hline Savio (Italy) & ARPA EMR & n.r & Adriatic Sea & 12.06 \\
\hline Seman (Albania) & Albanian Hydrometeorological Institute & $1948-1987$ & Adriatic Sea & 86 \\
\hline Shkumbi (Albania) & Albanian Hydrometeorological Institute & $1948-1991$ & Adriatic Sea & 58.7 \\
\hline Sile (Italy) & ARPA VENETO & n.r & Adriatic Sea & 52.92 \\
\hline Simeto (Italy) & GRDC & $1978-1980$ & Ionian Sea & 3.31 \\
\hline Sinni (Italy) & CNR IRPI & $1937-1976$ & Ionian Sea & 20.58 \\
\hline Tagliamento (Italy) & ARPA VENETO & n.r & Adriatic Sea & 96.92 \\
\hline Thyamis (Greece) & GRDC & $1963-1978$ & Ionian Sea & 51.39 \\
\hline Tronto (Italy) & Raicich (1996) & $1956-1965$ & Adriatic Sea & 17.92 \\
\hline Uso (Italy) & ARPA EMR & n.r & Adriatic Sea & 6 \\
\hline $\begin{array}{l}\text { Vibrata to Fortore + Pescara + San- } \\
\text { gro + Trigno + Biferno (Italy) }\end{array}$ & Raicich (1996) & $1956-1965$ & Adriatic Sea & 190 \\
\hline Vjiose (Albania) & Albanian Hydrometeorological Institute & $1948-1987$ & Adriatic Sea & 189 \\
\hline Zellina (Italy) & ARPA VENETO & n.r & Adriatic Sea & 10.28 \\
\hline Zrmanja (Croatia) & Pasaric (2004) & $1947-2000$ & Adriatic Sea & 40.10 \\
\hline Zrnovnica (Croatia) & Pasaric (2004) & $1947-2000$ & Adriatic Sea & 1.76 \\
\hline
\end{tabular}

Some of the datasets consist of observations taken at hydrometric stations and some are estimated values. To note that Po di Levante and Po di Volano are point sources different from the nine branches of the Po delta. Po river runoff values are not included in this Table since daily averaged observations are assumed at each branch of the delta based on Pontelagoscuro station

$\left(5.19 \times 10^{3} \mathrm{~m}^{3} \mathrm{~s}^{-1}\right), 2009\left(5.37 \times 10^{3} \mathrm{~m}^{3} \mathrm{~s}^{-1}\right)$, and 2010 $\left(5.26 \times 10^{3} \mathrm{~m}^{3} \mathrm{~s}^{-1}\right)$. The daily and annual maximum values are due to Po river only, as the other rivers consist of monthly climatologies. As detailed above, the Po river represents the largest contribution to the total discharge of the Central Mediterranean Sea, however we should consider we are missing the daily and interrannual variability coming from the other rivers.

The interannual variability described above is the result of only Po river runoff interannual differences because daily data sets for other rivers are not available for such an extended time period.

\subsection{River parameterization in the model}

Model rivers are parameterized as "surface sources" of water at the estuary border grid points while no temperature information is prescribed. Our assumption of no temperature differences between river inflow and the marine environment is generally valid as river plumes are controlled by the salinity gradients.

The runoff and salinity values are prescribed at river outlets in the vertical velocity and salt flux boundary conditions respectively. Here we follow the natural boundary condition approach (Huang 1993) plus ad-hoc salt values at river outlets, this is the most consistent before rivers will be considered with lateral open boundary conditions. Such boundary condition involves both a water and salt flux condition, as written in Eqs. (20) and (21), in order to conserve the volume integrated salt content in the basin. It can be easly demonstrated that by taking the volume integral of advection/diffusion equation for salinity and by replacing the boundary conditions (20) and (21) we obtain the salt conservation regardless of the constant value of salinity chosen at river mouths.

Kourafalou et al. (1996) implemented for the first time the natural boundary condition to the riverine freshwater flux, followed by Skliris et al. (2007), Beuvier et al. (2010), Dell'Aquila et al. (2012) and Vervatis et al. (2013). In addition operational models of the Mediterranean Sea already use the natural boundary condition from several years (Oddo et al. 2009).

Following Simoncelli et al. (2011) we prescribe constant salinity values at all river mouths parametrizing the effects of tidal mixing inside the river estuaries. Values chosen are equal to 15 psu for all rivers, except for the Po 
Fig. 3 River discharge into the Central Mediterranean Sea during the entire simulation period, 1999-01-01 to 2012-12-31.

Top panel Daily time series of total discharge. Black line is the discharge of all rivers flowing into the model domain. Green line is the discharge of Po river, which is the only one based on ARPA ERM daily observations. Magenta line is the contribution of all rivers, except Po, which are based on monthly climatologies. Middle panel Daily time series of Po river discharge. Comparison among observed runoff and daily interpolation of Raicich's climatologies (1996) and Ludwig's climatologies (Ludwig et al. 2009). Bottom panel Climatologies of the Adriatic rivers. Comparison of our model dataset with Raicich's and Ludwig's ones
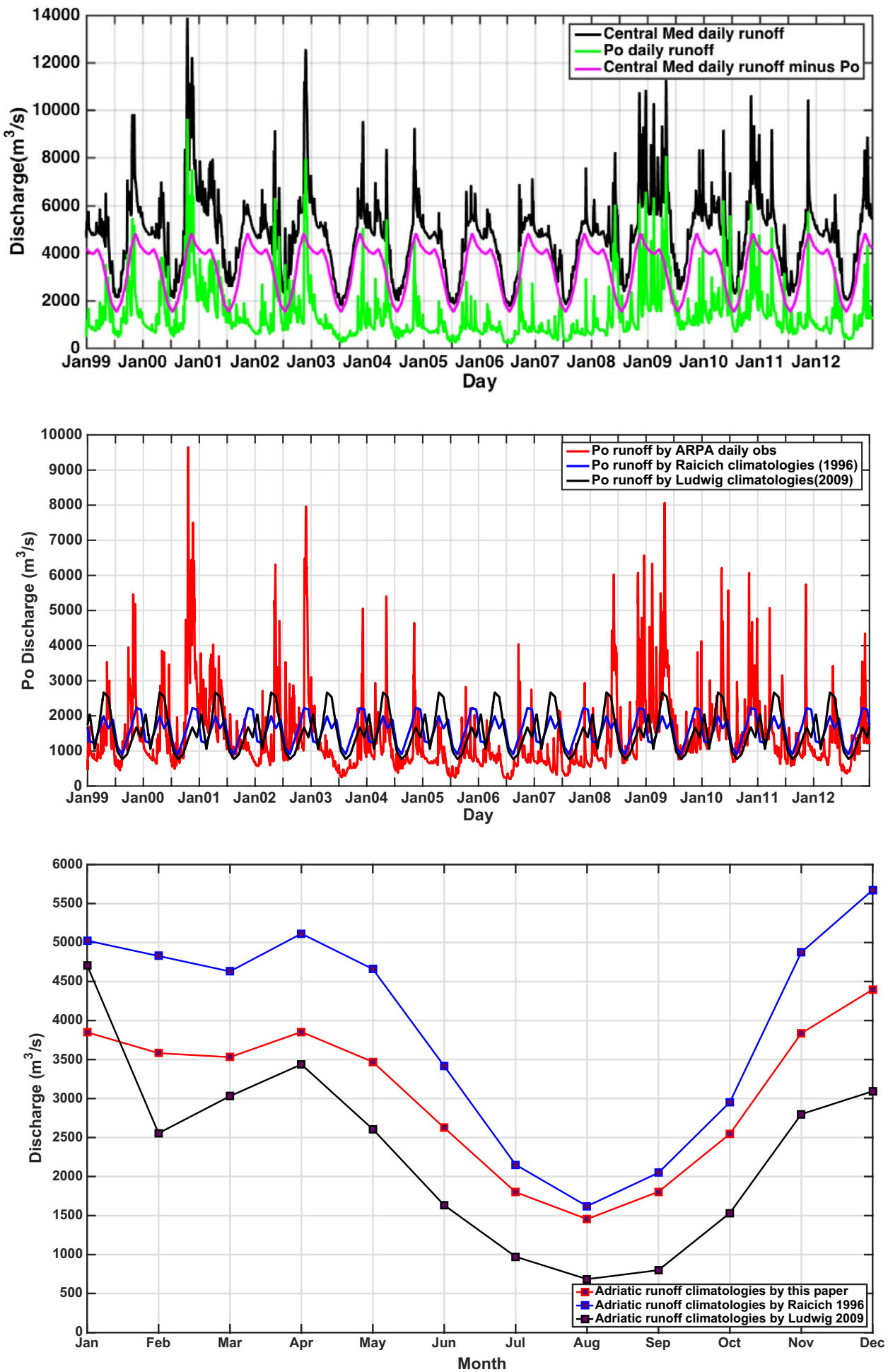

river where 17 psu is considered. These constant salinity values are the result of sensitivity tests performed on the basis of salinity profiles measured at river mouths (Simoncelli et al. 2011) and at the center of the basin (Oddo et al. 2005).

\subsection{Model validation with observations}

The performance of EXP1 was evaluated by comparing the simulated fields with available in situ observations. For the in situ data, two Argo profiling floats in the Adriatic and Ionian Seas (Fig. 4) were used to calculate vertical mean profiles 


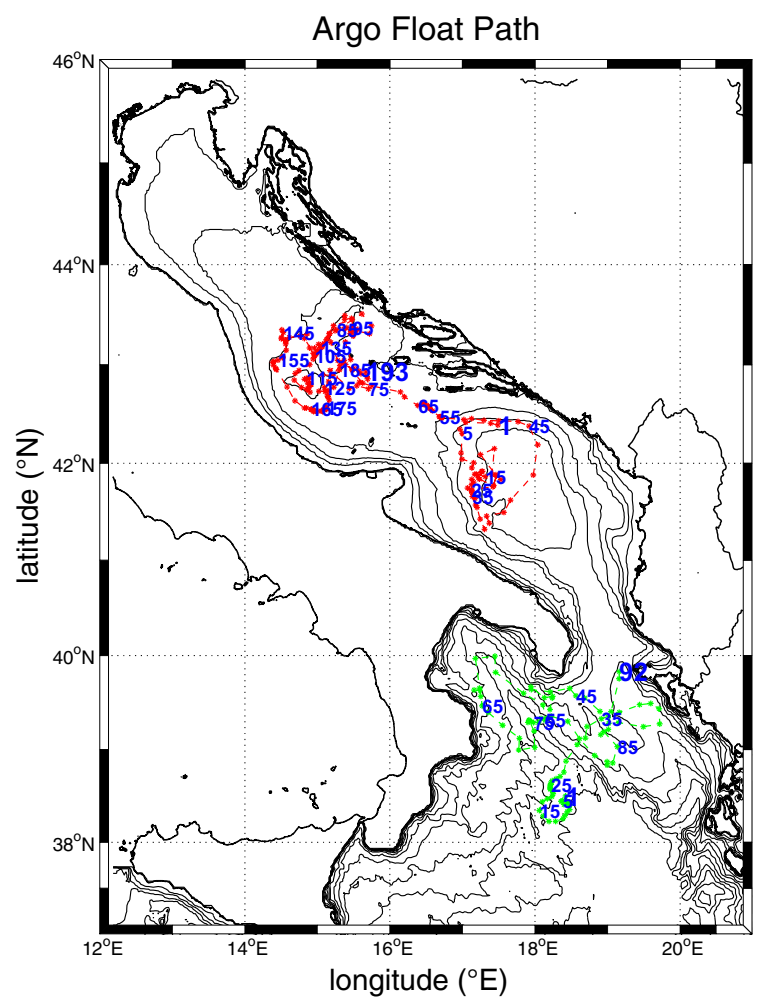

Fig. 4 The trajectory of two Argo profiling floats over 2010-2012. Numbers indicate the ascending profiles: 193 into the Adriatic Sea and 92 into the Ionian Sea

of RMSE and BIAS for temperature and salinity (Fig. 5). The profiles are in the area of deep water formation and in the northern Ionian exit, so in the most relevant places for our simulations. On the whole, EXP1 is in good agreement with the observed data, comparable RMSE and BIAS values were found for different models of the Adriatic Sea (Guarnieri et al. 2013) and the Ionian Sea (Federico et al. 2016; Kassis et al. 2016). In EXP2 without rivers, water masses in the Adriatic Sea appear saltier and warmer with respect to the observed dataset. EXP2 has then doubled the RMSE and BIAS errors with respect to observations thus showing already a large impact of rivers on the estimate of the circulation in the Adriatic Sea. The mean profiles of RMSE and BIAS do not show significant differences in the Ionian Sea instead.

Basin-averaged timeseries of analysed and modelled sea surface temperature are shown in Fig. 6. Analysed SST is obtained by Optimal Interpolation of Pathfinder AVHRR (Advanced Very High Resolution Radiometer) SST data (Pisano et al. 2016). Model results are characterized by a positive BIAS but are capable to reproduce the observed interannual variability. The agreement between model and analyses timeseries is high, with correlations of about $99.6 \%$ and RMSE is $0.8^{\circ} \mathrm{C}$ for EXP1.

\section{Discussion on the results}

\subsection{Is the Adriatic Sea an estuarine or anti-estuarine basin?}

The literature contains ample evidence that the MOC is primarily driven by wind and tidal stirring (Munk and Wunsch 1998; Paparella and Young 2002; Marshall and Speer 2012). In addition, the relationship between the dense water formation, driven by buoyancy fluxes, and the strength of the overturning circulation has been highlighted in several theoretical, as well as realistic modelling studies (Rahmstorf 1995, 1996; Pisacane et al. 2006). Similarly, here we focus on the downwelling branch of the Central Mediterranean MOC, which develops inside the Southern Adriatic sub-basin due to the local openocean convection and dense water formation sustained by winter heat losses and a cyclonic gyre driven by wind stress curl.

In this section we will describe both the surface forcing and the newest theoretical framework which connects the anti-estuarine and estuarine character of a marginal sea to the vertical overturning circulation.

\subsubsection{The surface forcing}

In order to assess the Adriatic Sea overturning circulation on the basis of surface forcing, an analysis of both buoyancy and wind stress fluxes was performed. The surface buoyancy flux per unit area, $Q_{B}\left(\mathrm{~m}^{2} \mathrm{~s}^{-3}\right)$ is calculated according to Cessi et al. (2014) as follows:

$Q_{b}=\frac{g \alpha_{T}}{\rho_{0 w} C_{w}} Q-\alpha_{S} S_{0} g(E-P-R / A)$

where $\alpha_{T, S}$ are the coefficients of thermal and haline expansion respectively, $\rho_{0 w}$ is the reference sea surface water density, $\mathrm{Q}$ is the net heat flux, $C_{w}$ is the heat capacity of sea water, $S_{0}$ is the surface salinity. Finally, $(E-P-R / A)$. is the freshwater flux with evaporation rate, $\mathrm{E}$, and precipitation rate $\mathrm{P}$, in $\mathrm{m} \mathrm{s}^{-1}$, river discharge $\mathrm{R}$ in $\mathrm{m}^{3} \mathrm{~s}^{-1}$ and A representing the grid area of river mouths $\left(\mathrm{m}^{2}\right)$. Furthermore the following values were assumed: $\alpha_{T}=2.3 \times 10^{-4} C^{-1}$, $\alpha_{S}=7.5 \times 10^{-4} \mathrm{psu}^{-1}, \quad C_{w}=3990 \mathrm{~J} \mathrm{~kg}^{-1}{ }^{\circ} \mathrm{C}^{-1}$, $S_{0}=38.7 \mathrm{psu}, \rho_{0 w}=1029 \mathrm{~kg} \mathrm{~m}^{-3}$. The net heat flux, $Q$, components are computed according to bulk formulae described in "Appendix 1".

Our results show the the whole Central Mediterranean Sea has a positive freshwater budget, $0.60 \mathrm{~m} \mathrm{year}^{-1}$, while the Adriatic Sea is negative, $-0.69 \mathrm{~m}$ year $^{-1}$, as expected.

The annual time series of Adriatic surface buoyancy flux and wind work is shown in Fig. 7. The realistic 

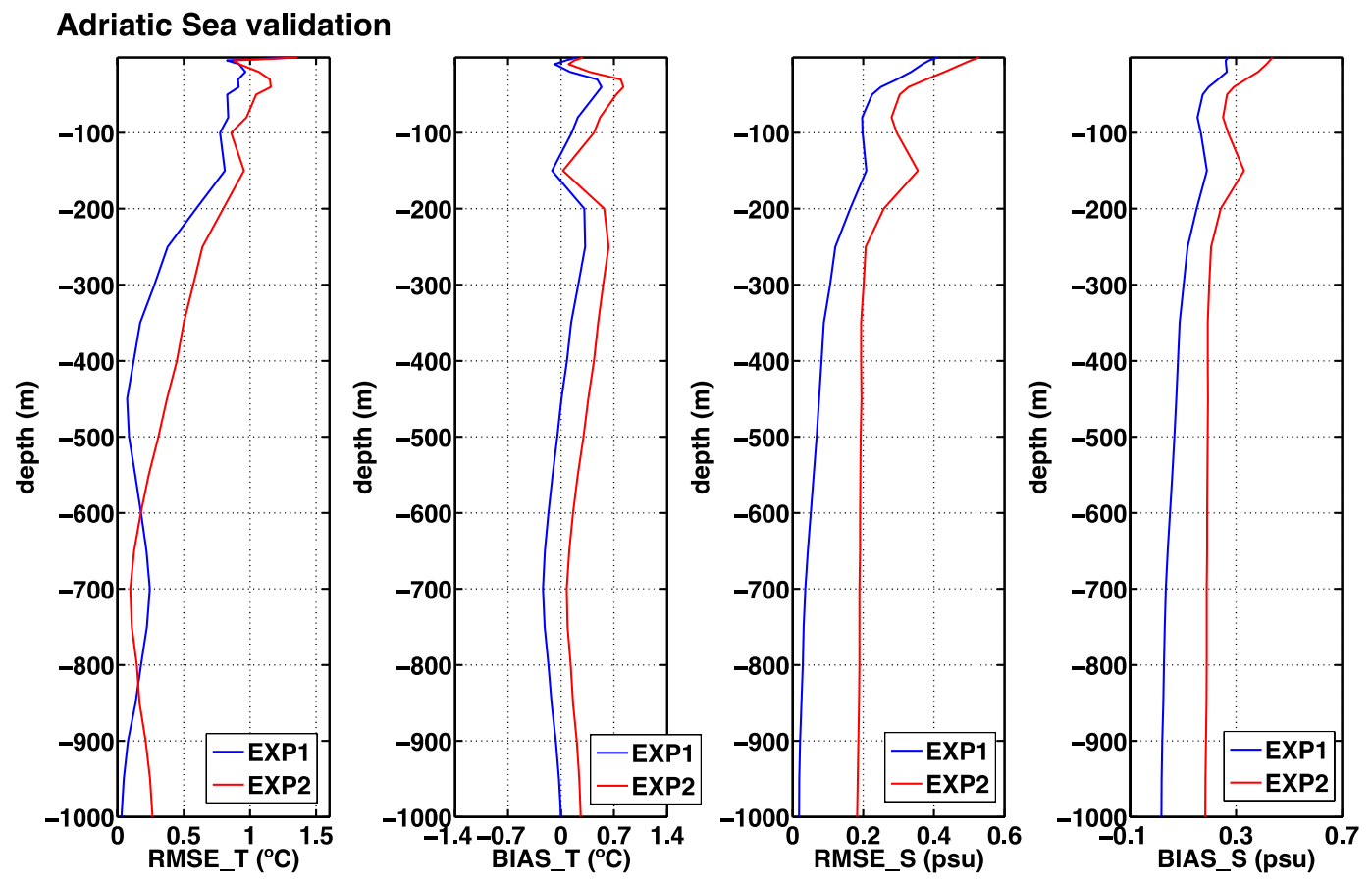

Ionian Sea validation
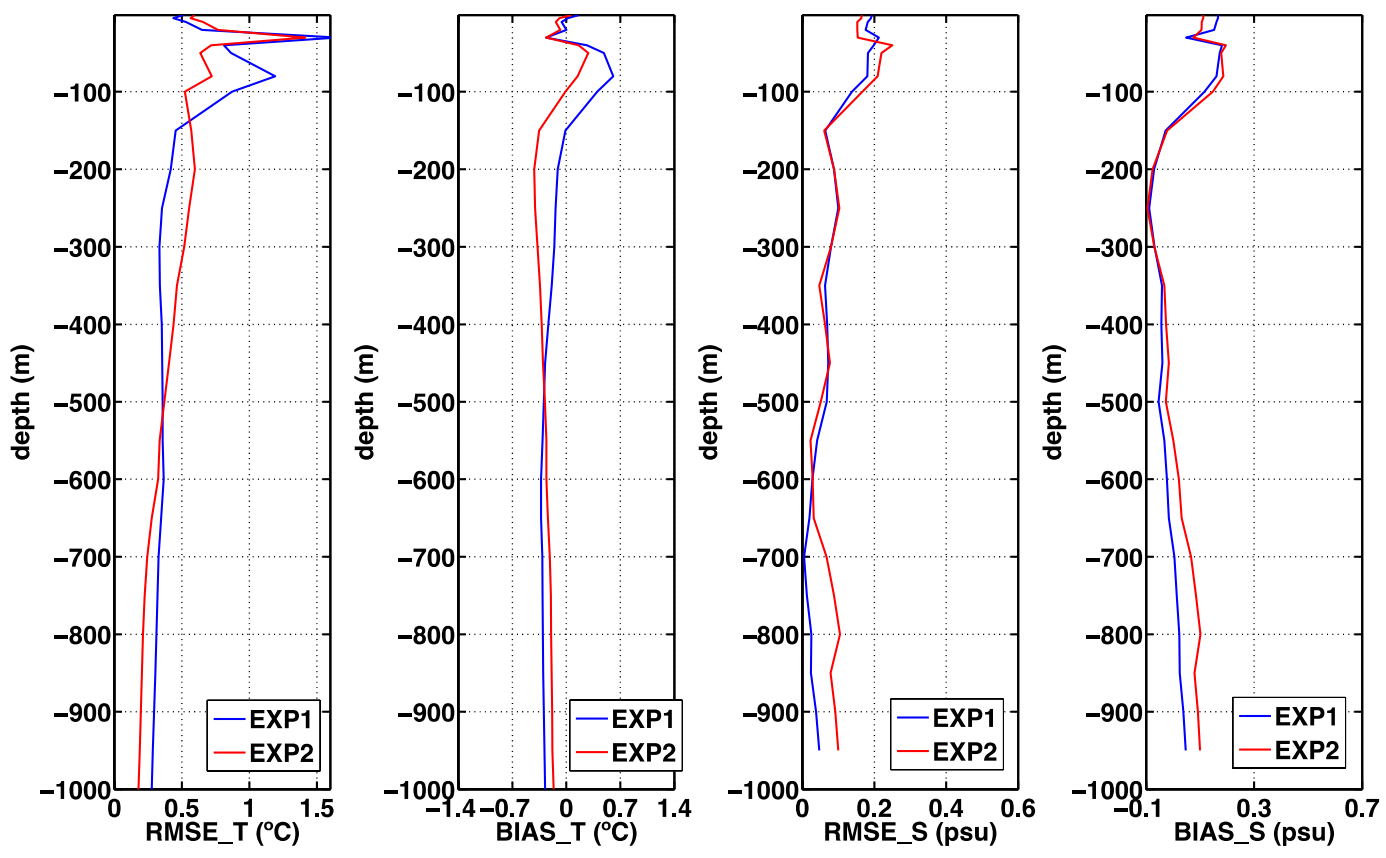

Fig. 5 Temperature and Salinity RMSE and BIAS for the available Argo observations over 2010-2012 in EXP1 and EXP2

buoyancy flux (EXP1) is generally negative, implying a net anti-estuarine forcing of the circulation, however in certain years, the values can be several times smaller and even change sign. This is the case for 2000,2002 and 2008 where the buoyancy flux reaches small or positive values. We argue that small or positive buoyancy budget could weaken the anti-estuarine $\mathrm{CMOC}$, as well as reduce the deep water formation processes in the Southern Adriatic Sea. The green line in Fig. 7, top panel shows the difference between the experiments, EXP1-EXP2, and reaches the maximum value in years 2002-2003, this means that in 2002 and 2003 the Adriatic buoyancy budget is mainly influenced by river runoff with respect to the other forcing mechanisms. A strong river release 
Fig. 6 Monthly time series of satellite (black line) and modelled (red line for EXP2 and blue line for EXP1) sea surface temperature
Fig. 7 Top panel Annual time series of buoyancy flux, $\iint^{Q_{b}} d A / A$, for EXP1 (blue line) and EXP2 (red line) and the relative difference. Bottom panel Annual time series of normalized averaged wind work, $\frac{1}{\rho_{0}} \iint \frac{\tau \cdot u_{s} d A}{V}$, for EXP1 and EXP2. Results are only relevant to the Adriatic Sea
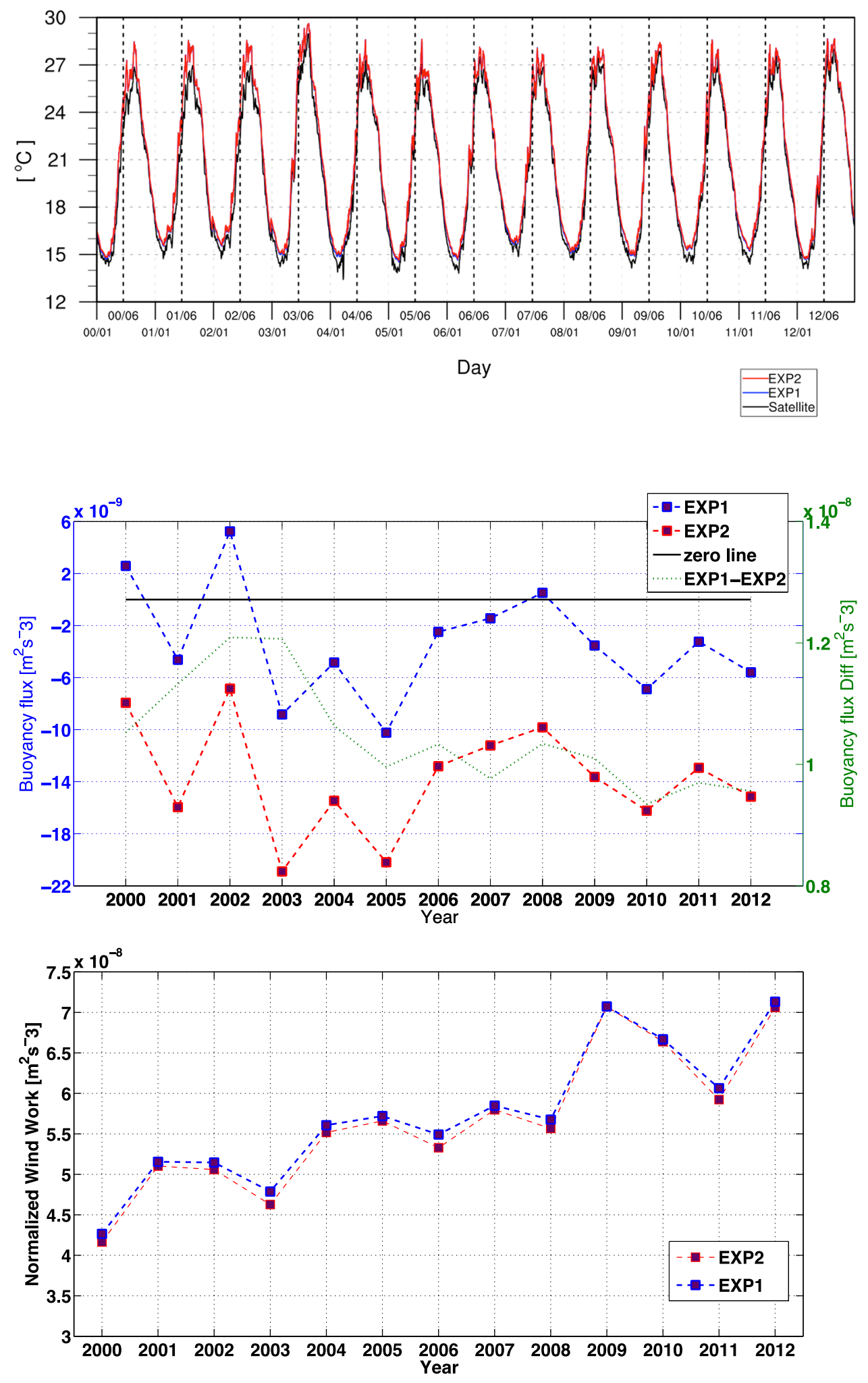

The wind work $\left(\mathrm{m}^{3} \mathrm{~s}^{-3}\right)$ is defined as $\mathrm{T}_{w} \cdot u_{s} / \rho_{0}$ where $u_{s}$ is the sea surface velocity, $\rho_{0}$ is the reference sea surface water density and $\mathrm{T}_{w}$ is the wind stress defined in occurred also in 2009 (see Fig. 3) but this year is characterised also by a intense wind work (Fig. 7, bottom panel) which makes river influence on the basin boyancy budget less relevant. 
"Appendix 1". The heat, freshwater and wind forcings acting at the air-sea interface may be directly compared by considering the buoyacy flux and the wind work: both quantities represent source/sink terms of energy. In order to compare the surface integrated buoyancy flux with the surface integrated wind work, the latter is integrated over the basin area and divided by the basin volume. Figure 7 shows that the wind work is always positive $\left(10^{-8} \mathrm{~m}^{2} \mathrm{~s}^{-3}\right)$, implying a net of mechanical energy for the Adriatic Sea that is one order of magnitude larger than the buoyancy flux $\left(10^{-9} \mathrm{~m}^{2} \mathrm{~s}^{-3}\right)$ in EXP1. Thus the Adriatic Sea results again to be an anti-estuarine basin characterized by a large wind work energy source.

\subsubsection{Theoretical marginal sea overturning estimates}

Spall (2011, 2012) analysed a marginal sea overturning circulation predicting that the freshwater input could stop the anti-estuarine circulation of a theoretical basin. Rahmstorf (1995) speculates that increasing freshwater inflow in the Northern Atlantic may potentially reduce or even shut down the overturning circulation. Cessi et al. (2014) show that both buoyancy forcing and wind stress work are connected to the strength of the circulation and thus, also to the MOC developing between the marginal sea and the open ocean.

Following Spall (2012) we assessed the non-dimensional thermal forcing parameter, $\mu / \varepsilon$, and freshwater forcing parameter, $\gamma / \varepsilon$. The former describes the relative balance between heat budget in the interior basin and the lateral eddy fluxes from the opening advecting warm water into the basin. The latter describes the relative balance between freshwater budget in the interior basin and the lateral salt eddy fluxes at the opening again. In the Adriatic Sea lateral eddy fluxes are advecting heat and salt through Otranto thus opposing the net heat loss and water gain (see previous sections): thus it is important to evaluate these nondimensional numbers to know how the lateral open boundary forcings work against the surface buoyancy flux. Small values of these parameters with eventually negative values of the freshwater parameter indicate that the lateral prevail over the surface cooling fliuxes in the basin interior and may trigger the shutdown of deep convection and then the reversal of the MOC.

We computed the two parameters over the whole simulation period and discovered that the thermal parameter is essentially the same in EXP1 and EXP2 experiments, $5 \times 10^{-5}$ in EXP2 and $4.9 \times 10^{-5}$ in EXP1, while the freshwater parameter is $7 \times 10^{-4}$ in EXP2 and $-2 \times 10^{-2}$ in EXP1 ("Appendix 2" for details on the computation of Spall's coefficients). This means that the Adriatic Sea runoff has the potential to shut down the deep convection and reduce the intensity of the antiestuarine CMOC.
Spall (2012) also shows that the non-dimensional ratio $\Delta S / \Delta T$, where $\Delta \mathrm{T}$ and $\Delta \mathrm{S}$ are respectively the model-diagnosed temperature and salinity non-dimensional anomalies between the interior basin and the open boundary currents, can be written as a function of the thermal and freshwater forcing parameters (see "Appendix 2" for details on the computation of these values). A ratio $\Delta S / \Delta T$ less than 1 means that the general circulation is in "thermal mode", which means that the heat forcing prevails and an antiestuarine MOC develops. A ratio $\Delta S / \Delta T>1$ indicates the "haline mode" of the marginal sea circulation with the shut down of deep convection and the possibility of an estuarine MOC if the freshwater budget is negative. The collapse of deep convection is demonstrated to be possible also in the thermal mode case if $\frac{\Delta S}{\Delta T}>0.5$.

We obtain $\Delta S / \Delta T=0.28$ and 0.12 in EXP1 and EXP2 respectively. Thus the Adriatic Sea is characterized by an anti-estuarine circulation with thermally driven deep water formation processes despite a large runoff budget. Focusing on the year 2002 which showed the largest river runoffs (Fig. 3), $\Delta S / \Delta T=0.42$ in EXP1 and 0.29 in EXP2, meaning that the Adriatic deep water formation and the antiestuarine circulation characterize both experiments with and without river runoff but EXP1 is close to the collapse of deep convection.

\subsection{How is the intensity of Central Mediterranean MOC affected by runoff?}

In order to better quantify the river influence on the CMOC, an inter-annual analysis of the meridional transport stream function was carried out.

The meridional transport stream-function, $\Psi$, is defined as (Pedlosky 1987):

$\Psi(y, z)=-\int_{x_{0}}^{x_{1}} \int_{-H}^{z} \overline{v(x, y, z)} d x d z$

with $-H<z<0$ as the depth, $x_{0}$ and $x_{1}$ the more eastern and more western sea points, $\bar{v}$ is the time-averaged meridional velocity. The velocity field is tangent to the isopleths of $\Psi$, and positive $\Psi$ values indicate anti-estuarine cells turning anti-cyclonically or clockwise, while negative values indicate estuarine cells turning cyclonically or anticlockwise.

Top panels of Fig. 8 show the transport stream-function for EXP1 and EXP2, averaged over the whole simulation period. A large anti-estuarine cell down to a $700-800 \mathrm{~m}$ depth is detected in both experiments in the Northern Ionian Sea and SAd sub-region, but with different intensities. Interestingly enough many estuarine cells exists in the domain: one at the surface in the NAd, one in the deep 

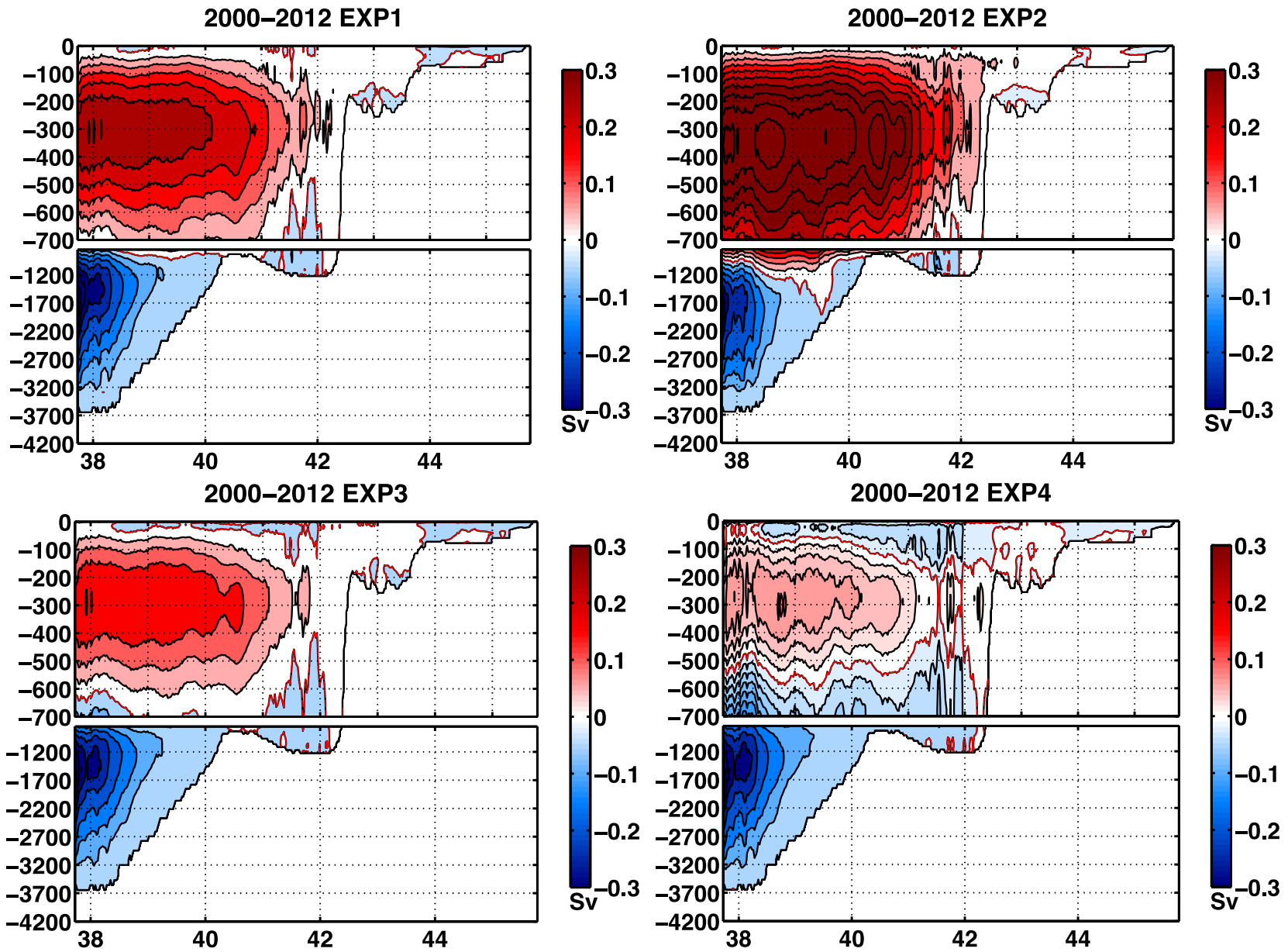

Fig. 8 Multiannual Meridional transport stream function for the Central Mediterranean Sea

layers of the Southern Adriatic Pit around $41-42^{\circ} \mathrm{N}$, SAP, another in the Middle Adriatic Pit around $43^{\circ} \mathrm{N}, \mathrm{MAP}$, and the last in the Northern Ionian abyss. The estuarine cells attached to the seabed represent a more stagnant circulation in the Adriatic Pits and Ionian abyss. To note that the estuarine cell which extends to the whole depth of the NAd is the consequence of a strong mixing of the entire water column (i.e. about $35 \mathrm{~m}$ depth) due to heat losses and wind stress. In the Ionian abyss the deep estuarine cell attached to the seabed below the CMOC is linked to the SAd dense waters overflowing the Otranto Strait and stratifying below the CMOC cell (Curchitser et al. 2001; Bensi et al. 2013a). Deep estuarine cells exist below the wind driven antiestuarine MOC cells of the mid-to-deep water depths of the global ocean as demonstrated by Nikurashin and Vallis (2011) and De Lavergne et al. (2016). Recently Ferrari et al. (2016) found that a deep overturning cell exists below the antiestuarine Atlantic MOC. This is due to the turbulent boundary layer very close to the sloping bottom of the deep abyssal plains, generating diapycnal upwelling below the Atlantic MOC. In the Mediterranean we can speculate that the same mechanism is present due to the complex topography and the slow abyssal cyclonic motion of deep water masses (Curchitser et al. 2001).

Top panels of Fig. 8 demonstrate that with both a zerorunoff and a realistic runoff case, the anti-estuarine character of the CMOC prevails. Indeed, in EXP1, the secondary estuarine cells of the NAd, MAd, SAd sub-regions and Northern Ionian basin are larger than in EXP2, however the anti-estuarine MOC cell still dominates.

The estuarine component of the MOC may become more evident on a seasonal basis, particularly during summer. Figure 9 focuses on summer 2002 and summer 2009 because these years had the largest spring river discharge (Fig. 3). In summer 2009 (Fig. 9, bottom panels), a welldefined surface estuarine cell characterizes the whole meridional extension of the basin with no differences between EXP1 and EXP2, which means that the wind forcing becomes a dominant contribution to the estuarine secondary cells. During this season the wind work is maximum (Fig. 7, bottom panel) but the buoyancy flux is still negative (Fig. 7, top panel) thus trying to force an 

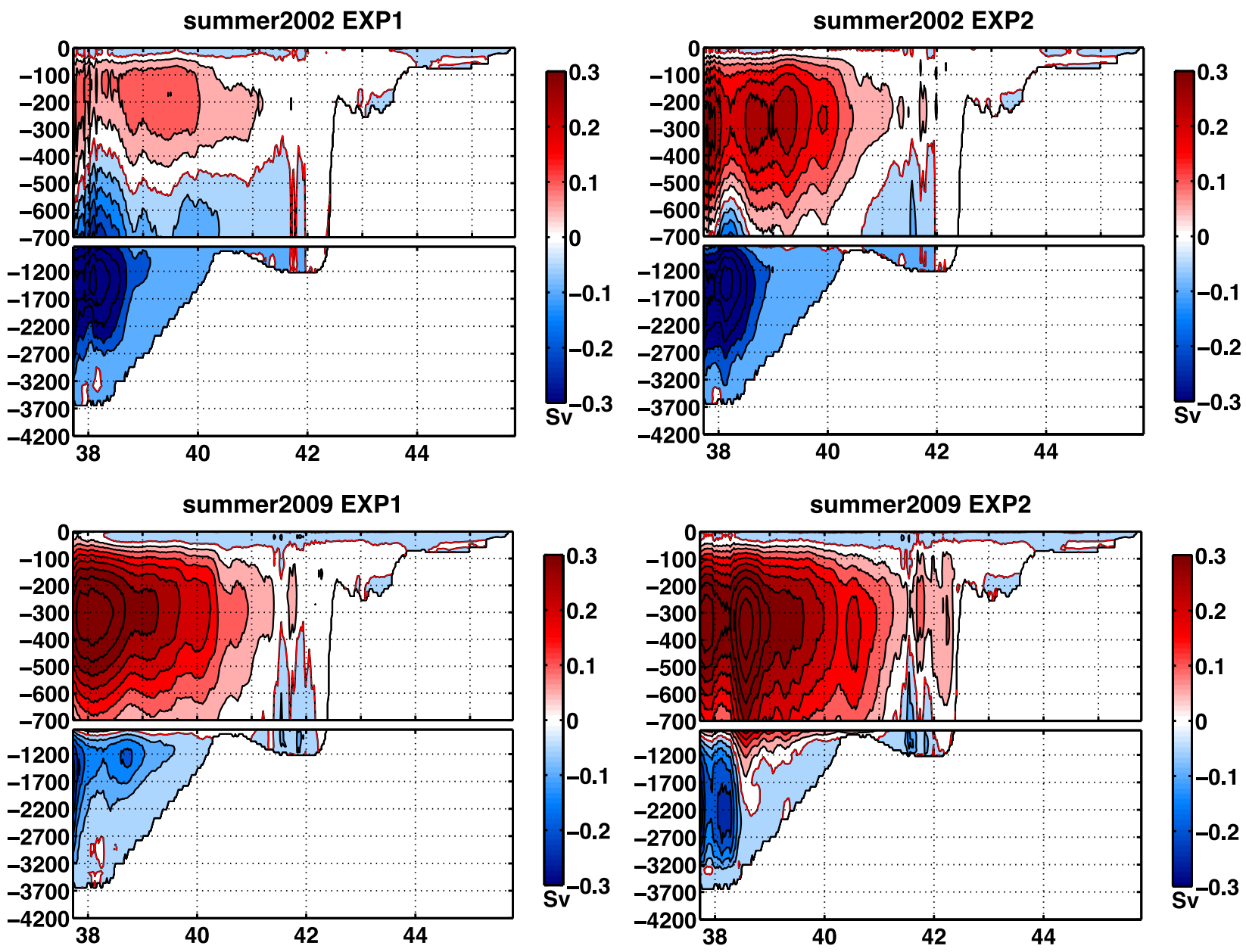

Fig. 9 Summer 2002 (top panels) and Summer 2009 (bottom panels) Meridional Transport Stream Function for the Central Mediterranean Sea

anti-estuarine MOC in the Adriatic Sea. In summer 2002 (Fig. 9, top panels), the river influence is more significant due to the weaker wind forcing and the positive buoyancy forcing. In EXP1 the anti-estuarine MOC is weak and restricted to 200-400 m depths, while the secondary estuarine cells are stronger. However even in this case the dominant overturning circulation is still anti-estuarine, in agreement with the Spall's (2012) freshwater and thermal forcing parameters predictions.

Two additional experiments, EXP3 and EXP4, have been performed by enhancing runoff of all rivers of 50 and $100 \%$ (Table 1). The bottom panels of Fig. 8 show an abrupt weakening of the CMOC strength in EXP3 and EXP4: the anti-estuarine cell does not disappear but reduces its intensity and extends only in the Northern Ionian sub-basin up to $400 \mathrm{~m}$ depth, while the surface estuarine cell is more pronounced and the deep estuarine cell of the Ionian abyss enlarges over the SAd. Overall the multiannual CMOC at middle depths remains an antiestuarine cell in all the experiments.
Figure 10 focuses on year 2001 as we found that in 2001 the middle depth antiestuarine cell disappears with both realistic (EXP1) and augmented runoff (EXP3 and EXP4). This is due to the weak wind work (Fig. 7, bottom panel) and the lowest heat budget (not shown). By comparing Figs. 9 and 10 we then conclude that a large river runoff can produce a positive buoyancy flux without switching off the antiestuarine CMOC cell (as shown in Fig. 9 for year 2002) but a low heat flux and wind work with normal river runoff can in fact reverse it (as shown in Fig. 10 for year 2001).

Overall by comparing the experiments with and without increased runoff, we demonstrate that rivers play a relevant role in the CMOC strength but they do not represent the dominant controlling mechanism.

Figure 11 provides the time series of the annual MTS for all the experiments, by considering the averaged value over 100-400 m depths in order to focus on the location of the anti-estuarine CMOC cell. These time series corroborate the previous result on river role in the CMOC strength. 

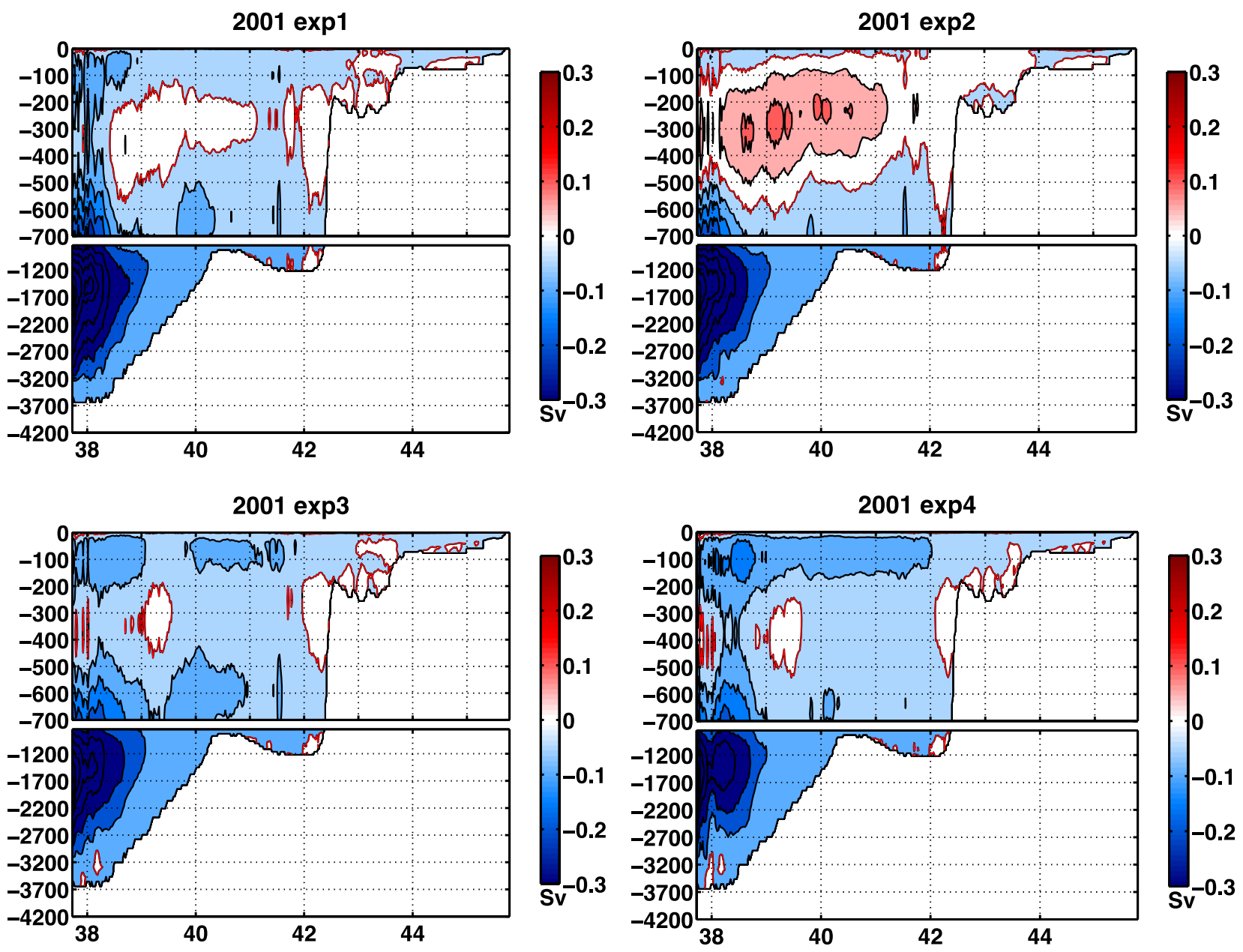

Fig. 10 Meridional transport stream function for the Central Mediterranean Sea over year 2001

Fig. 11 Time evolution of the Meridional transport stream function averaged over $100-400 \mathrm{~m}$ depths for all the experiments

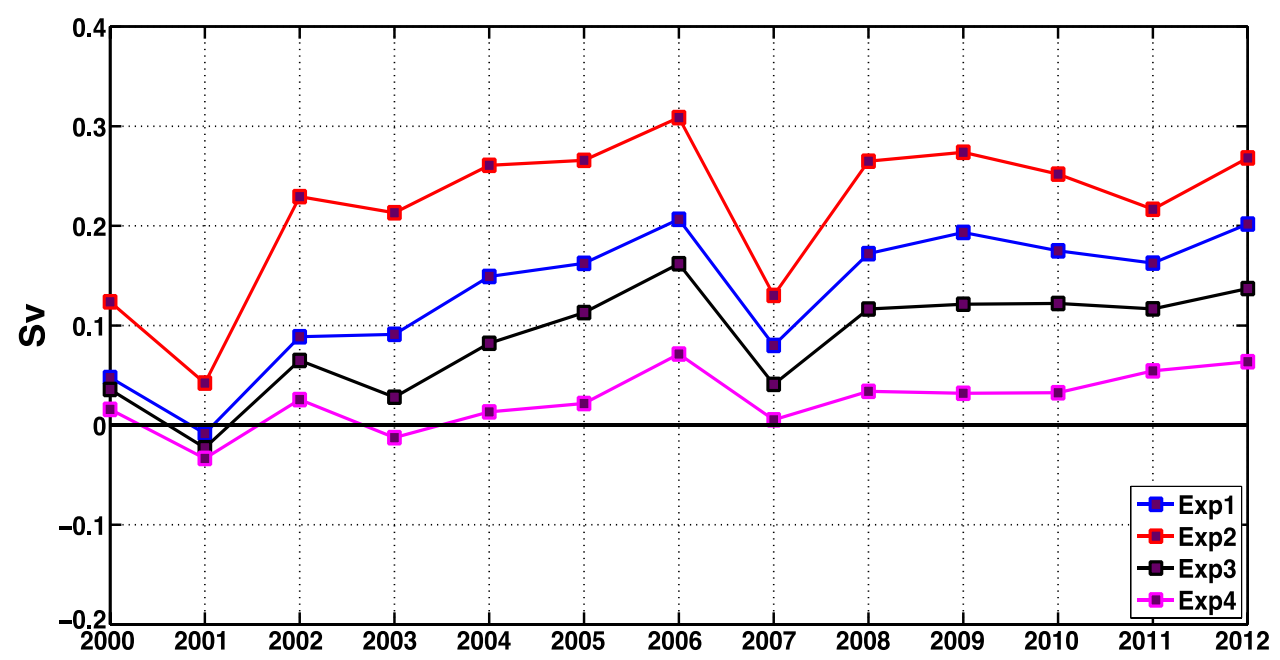

As expected, EXP2 with zero-runoff shows the highest values of the middle depth MTS and EXP4 the lowest ones. The EXP4 retains positive values of the middle depth MTS through the whole simulation period due to the dominant anti-estuarine CMOC cell, except for the years 2001 (along with EXP1 and EXP3, as shown in Fig. 10) and 2003. 
As far as we know an analysis of the MOC for the Eastern Mediterranean (EMOC) has been performed only by Pisacane et al. 2006 and Amitai et al. (2016). Pisacane (Pisacane et al. 2006) EMOC cell resembles our CMOC cell intensity and extension with a well defined antiestuarine character but this cell is computed over a different model domain and the interannual average is shown only for the summer time. Amitai et al. (2016) evaluated the MOC in the Adriatic basin: their maximum value of $0.5 \mathrm{~Sv}$ is comparable with our results, which show a maximum value of about $0.3 \mathrm{~Sv}$ at $300 \mathrm{~m}$ depth close to the Otranto Strait (Fig. 8, left panel). However Amitai et al. (2016) differs because the antiestuarine cell is restricted only to the southern part of the SAd Pit while an additional estuarine cell occupies its northern part.

\subsection{How do rivers influence the formation of dense water in the Adriatic Sea?}

The aim here is to establish how rivers impact the dense water formation processes in the Southern Adriatic Sea and thus impact the CMOC. The conditioning factors of opensea convection and dense water formation in the Southern Adriatic are known to be the permanent cyclonic gyre sustained by wind stress curl, the large buoyancy losses, mainly known to be due to large heat losses, and the inflow of LIW through the Otranto Strait. Moreover the SAd deep layers are partially filled by the NAd dense water which partially the MAd Pit and partially flows southward over the Italian western shelf and reaches the Bari Canyon, usually 2 months after its generation. Here the boundary current of NAd dense water mixes turbulently with adjacent warmer and less saline waters and sinks to the Southern Adriatic Pit (Vilibić and Orlić 2001; Bensi et al. 2013b).

Figure 12 shows the dense water volume formed in the NAd, MAd and SAd sub-regions computed as the water volume with larger potential density anomaly than the threshold value, $29.2 \mathrm{~kg} \mathrm{~m}^{-3}$.

In the NAd, where the major discharge is concentrated, buoyancy gains due to river runoff oppose the preconditioning factors of DW formation i.e. the winter surface cooling, the outbreaks of cold and dry wind like Bora and the autumn/winter NAd cyclonic gyre (Fig. 12, top panel). Rivers may affect DW volume also in the MAd as they reduce the DW advected from the NAd (Fig. 12, middle panel).

Looking at the full dynamics experiment (EXP1) we find that the mean DWF rate of $0.3 \mathrm{~Sv}$ is consistent with the literature estimates (Artegiani et al. 1989, 1997a, b; Lascaratos 1993; Cushman-Roisin et al. 2002; Curchitser et al. 2001; Manca et al. 2002; Mantziafou and Lascaratos 2004, 2008; Pinardi et al. 2015). The interannual formation rates match the recent estimates by Oddo and Guarnieri (2011) and by Gunduz et al. (2013): the collapse of
DW formation in winter 2000-2001 and the lowering in 2007 looking at the NAd sub-region, the absence of dense water over 2000-2003 in the MAd and till 2005 in the SAd which is known to be linked to reduced MLIW inflow and high temperature; the high dense water formation in 2006. There is a perfect agreement with DW volumes found by Gunduz et al. (2013) and the SAd DW formation fits the observations by Cardin et al. (2011). Our results also confirm the exceptional dense water formation in winter 2012 as consequence of an extreme wintertime cooling event, which produces DW volumes capable to saturate the volume of NAd, i.e. $2357 \mathrm{~km}^{3}$, and MAd, i.e. $4039 \mathrm{~km}^{3}$, subregions (Mihanović et al. 2013; Janeković et al. 2014). On the other hand our estimated SAd DW volumes are pretty higher with respect to Oddo and Guarnieri (2011). In our full dynamics experiment, EXP1, we found the transport of NAd dense water toward the middle Adriatic had a peak value of $1.6 \mathrm{~Sv}$ in 2012 while $0.6 \mathrm{~Sv}$ is found by Janekovic' et al. (2014), actually defined over a smaller region thus cannot be directly compared. Our SAd DW formation annual rate reaches the peak of $1.52 \mathrm{~Sv}$ in 2006, higher then 0.64 Sv estimate by Oddo and Guarnieri (2011) but our estimate is consistent with the known potential peaks of SAd DW rates, following Mantziafou and Lascaratos (2008) and Vilibic and Supic (2005).

We found EXP2, without river forcing, shows 20-30\% larger SAd dense water volumes than EXP1. Previous studies suggest that rivers affect SAd dense water volumes because they reduce the lateral advection of NAd dense waters which are known to flow along the western shelf and slide down into the Southern Adriatic Pit near the Bari canyon (Vilibić and Orlić 2001-2002; Mantziafou and Lascaratos 2004, 2008; Wang et al. 2007). However, we found this mechanism is not sufficient to account for EXP1 and EXP2 SAd dense water volume difference because the latter is larger than the sum of NAd and MAd dense water volume differences between EXP1 and EXP2. This means that rivers affect SAd dense water volumes not only by reducing the lateral advection of NAd dense water but they also oppose the local preconditioning factors of the dense water formation in the SAd, i.e. the "open sea convection" mechanism, as they locally change the vertical stratification characteristics.

To explain the river impact on the open sea convection, Fig. 13 shows seasonal $\theta-S$ diagrams in three Adriatic subregion zonal sections for winter 2009. The main difference between EXP1 and EXP2 $\theta-S$ diagrams is the degree of stratification of the water column: river runoff determines a well stratified water column in all the three subregions and different water types with characteristic $\theta$ and $S$ values can be distinguished. On the other hand the no-river case, EXP2, shows an almost constant salinity value in the three zonal sections. 
Fig. 12 Daily averaged time series of water volumes with $\sigma_{\theta}>29.2 \mathrm{~kg} \mathrm{~m}^{-3}$ in the NAd (top panel), MAd (middle panel) and SAd (bottom panel) sub-regions. The blue line stands for EXP1, the red line for EXP2
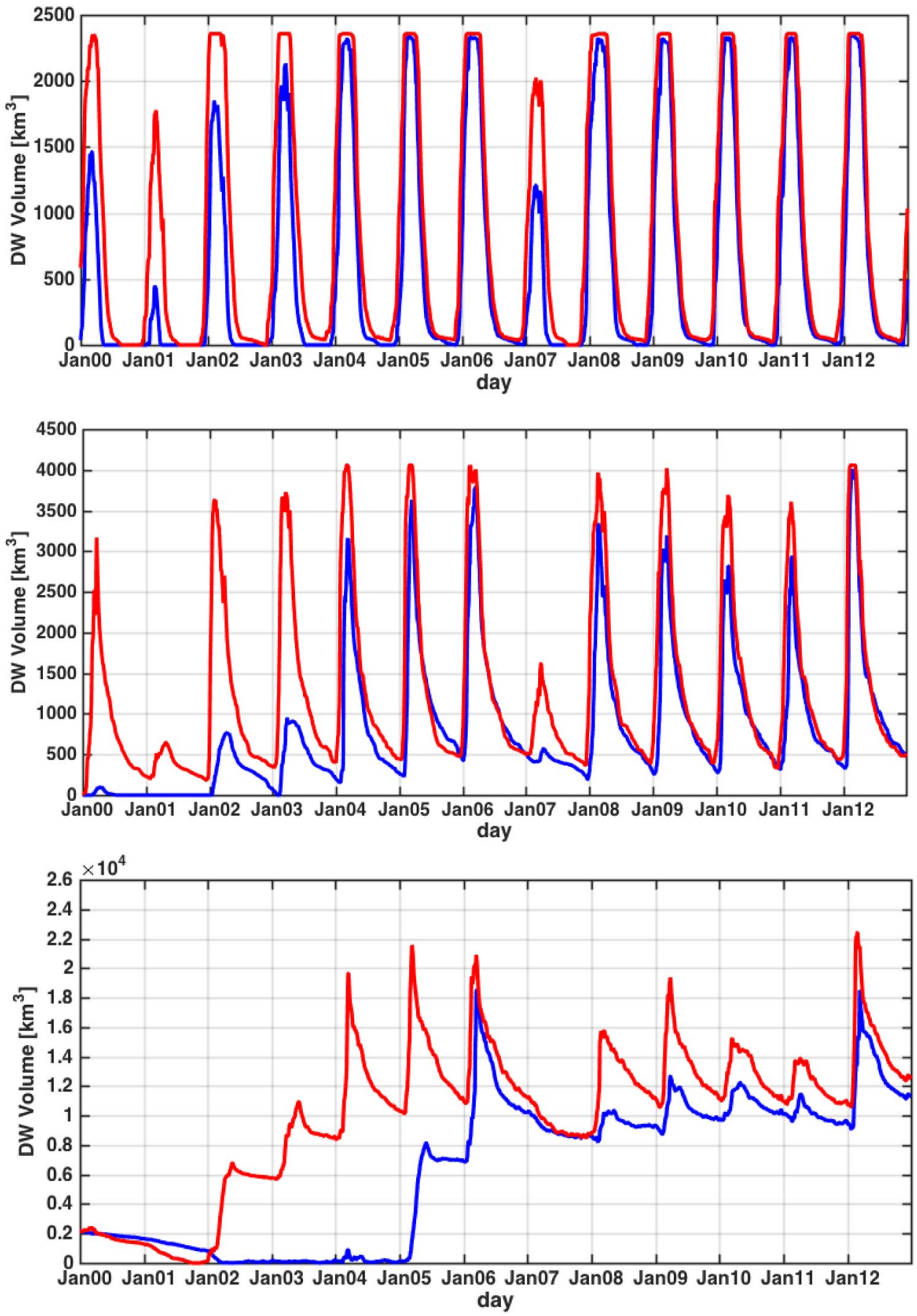

Thus we conclude that river runoff primarily influences the dense water formation processes by changing the SAd vertical stratification characteristics. However these stratification changes can determine changes in the CMOC characteristics only if the overall buoyancy forcing is positive, as shown for the 2002 case. In the 2009 case, wind stress work is large and buoyancy forcing still negative, thus balancing the large river runoff stratification effects and producing no relevant changes in the CMOC.

\subsection{How do rivers influence the Otranto water exchange and the volume of Adriatic dense water that spreads into the Northern Ionian Sea?}

Figure 14 shows the Otranto inflow-outflow regime for EXP1 and EXP2. EXP2 shows an "horizontally detached" exchange flow with inflowing water on the eastern side and outflowing water on the western one. EXP1 shows a weaker exchange pattern with lower meridional velocity through 

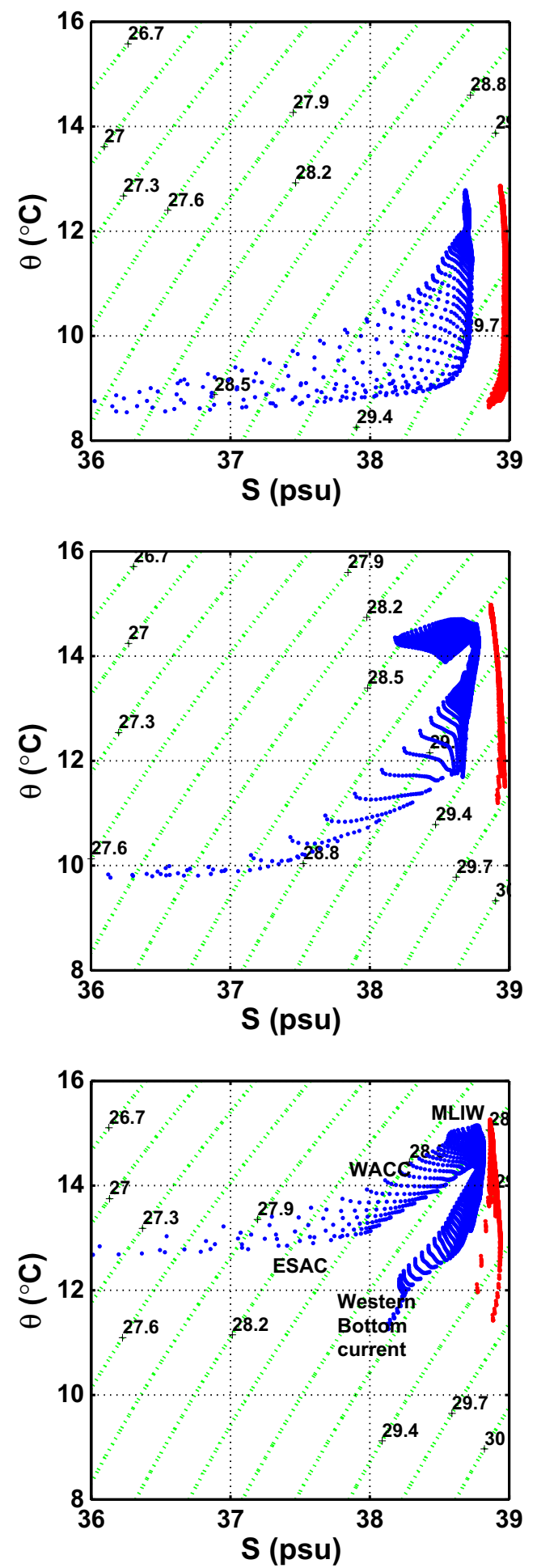

Fig. 13 - $\theta$-S diagram in winter 2009 for EXP1 (blue dots) and EXP2 (red dots) in three zonal sections related to NAd sub-region at $44.38^{\circ} \mathrm{N}$ (top panel), MAd at $42.6^{\circ} \mathrm{N}$ (middle panel) and SAd at $41.61^{\circ} \mathrm{N}$ (bottom panel), respectively. The Western Adriatic Coastal Current, WACC, the Eastern Southern Adriatic Current, ESAC, the Western bottom current and the Modified Levantine Intermediate Water, MLIW, are marked in the bottom panel according to the known range of temperatures and salinities all depths and strong exchange flux narrowed to the upper levels.

We know that the Modified Levantine Intermediate Water, MLIW, arriving from the Rhodes area of formation occasionally enters the Adriatic Sea mainly in summer and autumn between 150 and $400 \mathrm{~m}$ (Malanotte-Rizzoli et al. 1997; Robinson et al. 2001; Manca et al. 2002; Mantziafou and Lascaratos 2004, 2008). Moreover it is well known from the literature that the SAd dense water overflows the Otranto Strait mainly along its western part (Curchitser et al. 2001).

Our modeling findings prove for the first time that rivers reduce both the MLIW inflow on the Eastern shelf and the SAd DW outflow on the western side.

The MLIW inflow is not systematic but depends on the cyclonic/anticyclonic character of the Ionian intermediate water circulation: our experiment covers most of the cyclonic decadal phase of the Ionian near-surface circulation, i.e. 1997-2007 (Gacić et al. 2010; Bensi et al. 2013a, b), which favors the entrance of MLIW into the Adriatic basin.

Timeseries of the meridional heat and volume transports at the Otranto Strait are provided in Fig. 15. Rivers are shown to reduce the net ingoing heat transport (Fig. 15, upper panel) and to increase the outgoing volume transport (Fig. 15, bottom panel). The annual values of heat and volume transports we found are fully consistent with the annual averaged heat gain, i.e. $2.92 \mathrm{TW}$, and volume outflow, i.e. $-0.003 \mathrm{~Sv}$, computed by Mantziafou and Lascaratos (2004).

Bottom panel of Fig. 15 confirms river role on the volume exchange at the Otranto Strait as already stressed in Fig. 14. Rivers increase the freshwater outflow at the surface, they reduce the inflow of salt and warm water on the eastern flank at the surface, i.e. the Ionian Surface Water (ISW), and middle depths, i.e. the MLIW; finally rivers reduce the outflow of Adriatic DW through the bottom (Cushman-Roisin et al. 2002), which represents only 30\% of the total outflow. Thus the overall effect is an increase of the total outflow at the Otranto Strait. Years 2005 and 2006 are the only ones with no differences in terms of volume transport between the two EXPs, because other forcings (e.g. surface heat losses, ISW and MLIW inflow) are prevailing on river freshwater forcing.

The Adriatic dense waters outflow the Otranto Strait and spread into the abyssal Ionian Sea, generally occupying the layer below the salt waters coming from the Cretan Sea and the Levantine basin (Roussenov et al. 2001; Curchitser et al. 2001; Bensi et al. 2013a).

Figure 16 shows the seasonal potential density anomaly of the $200 \mathrm{~m}$ layer above the seabed in both EXP1 and EXP2 and their differences with a zoom on the Ionian Sea. The maps show spring 2012 because this was the year with 

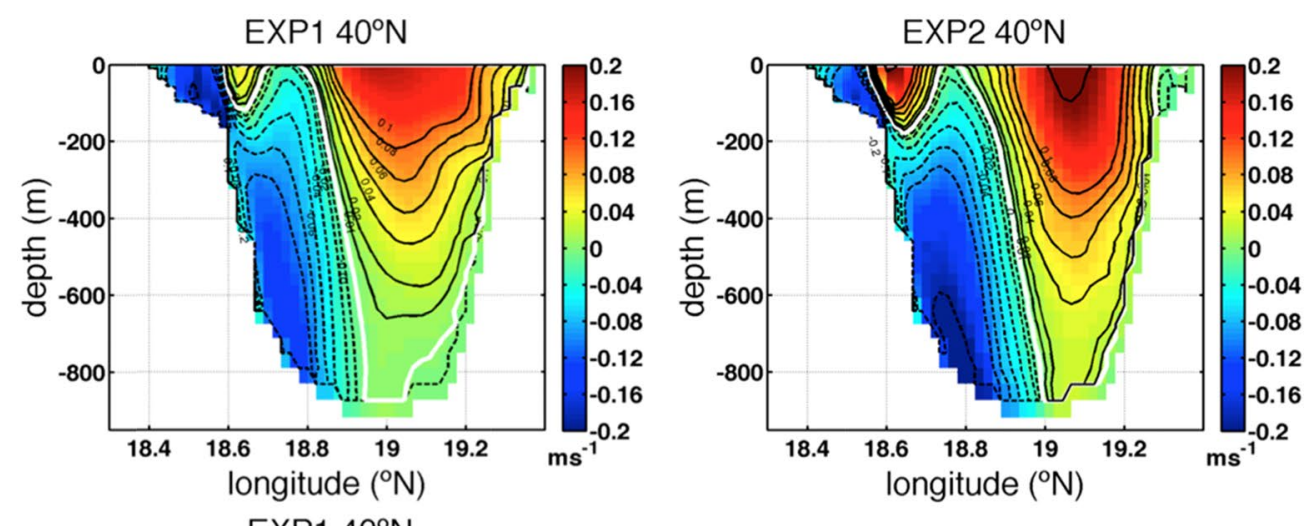

\section{WINTER}
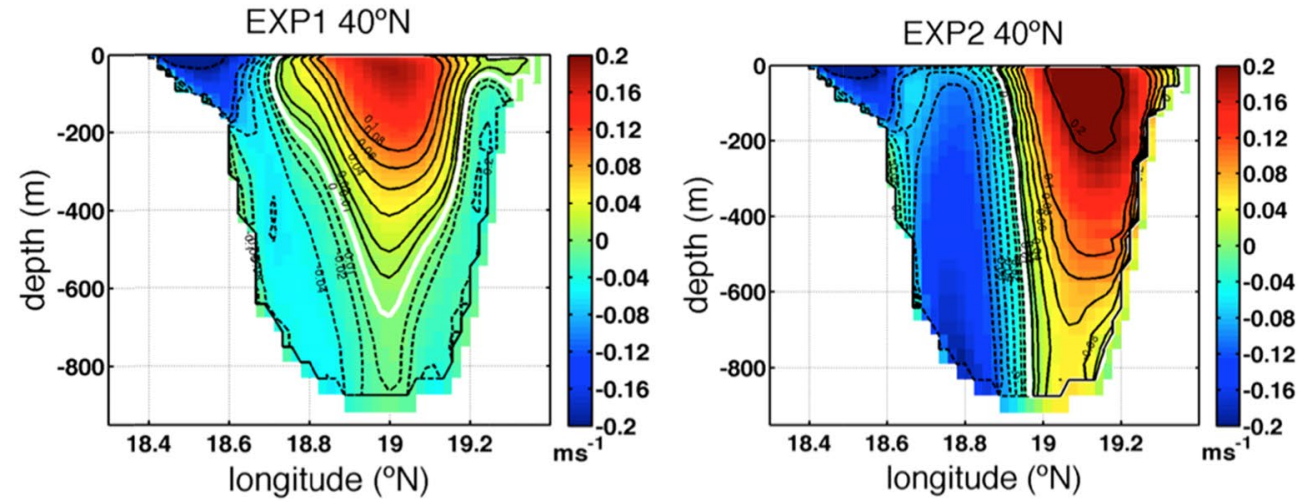

\section{SPRING}
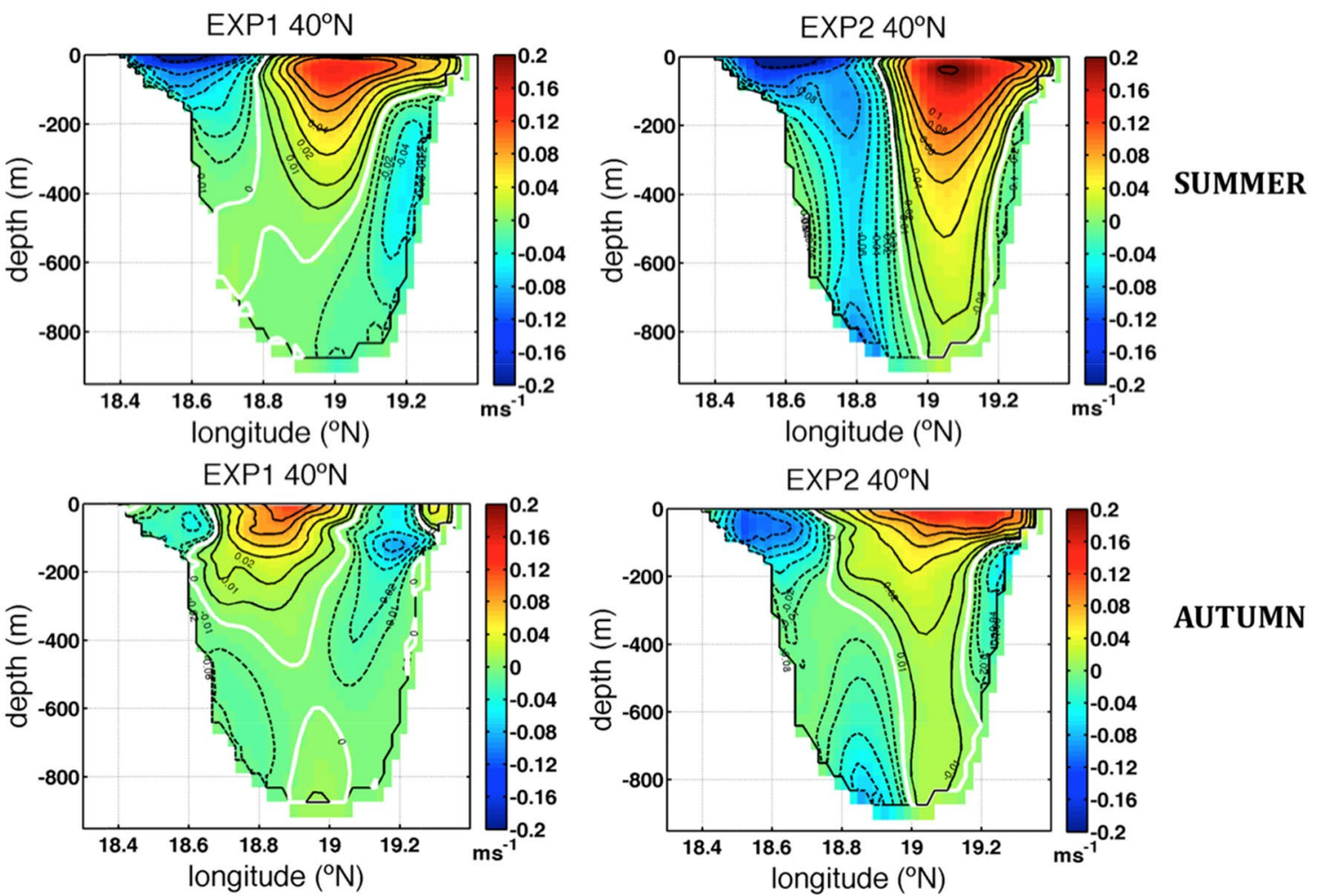

Fig. 14 Transect of the meridional velocity at the Otranto channel (i.e. $\left.40^{\circ} \mathrm{N}\right)$. Firm lines mean inflow, dashed lines mean outflow, the while line stands for zero meridional velocity 
Fig. 15 Upper panel Annual time series of heat transport (units are TW) at the Otranto Strait. Bottom panel Annual timeseries of meridional volume transport (units are Sv) at the Otranto Strait. Positive values mean northward or ingoing transport, negative values southward or outgoing transport
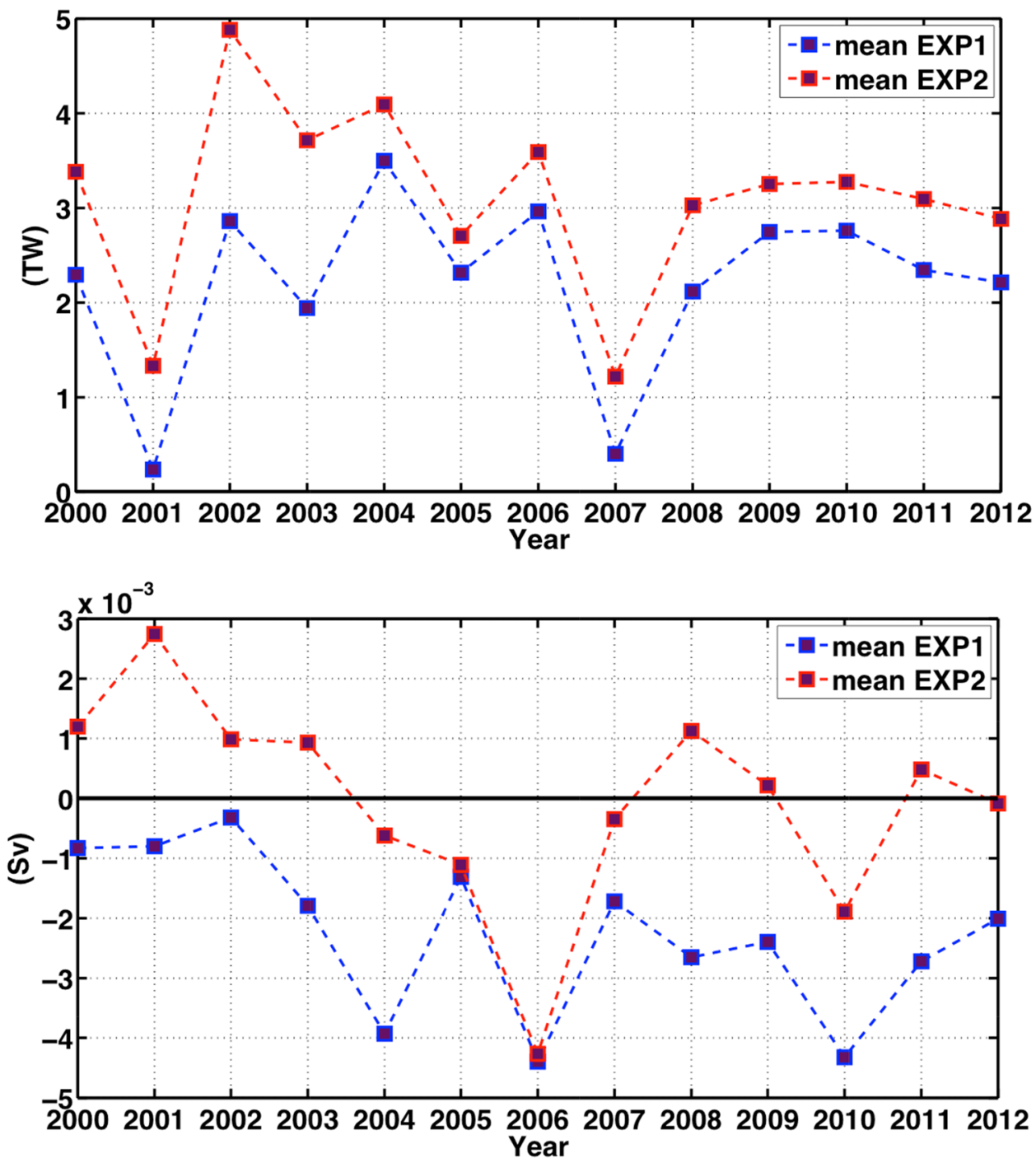

one of the largest dense water volume formation (as shown in Fig. 12).

SAd dense water initially spreads into the Northern Ionian Sea following the topography. The Adriatic outflowing dense water is known to move mainly along the isobaths on the Italian shelf at about 600-1000 $\mathrm{m}$ in almost geostrophic balance (Budillon et al. 2010), a secondary branch follows a meridional path driven by the local bathymetry (Hainbucher et al. 2006); both branches slowed down and sink due to friction and turbulent mixing with the ambient waters, thereby creating a nearly homogeneous layer below $1200 \mathrm{~m}$ (Curchitser et al. 2001). Wu and Haines (1996) found newly formed Adriatic dense waters fill the Ionian abyss in 2-3 years.

Figure 16 shows that the bottom boundary current forced by dense water outflow from the Otranto Strait is characterized in EXP1 by less dense waters that intrude offshore with respect to EXP2 as expected. Furthermore the Adriatic dense water outflow in EXP2 is confined to a narrower band against the Italian shelf with less lateral spreading toward the Ionian Seaia. This suggests that river runoff has consequences on the Northern Ionian Sea water mass structure and abyssal mixing processes. It is interesting to connect such outflow differences with the abyssal estuarine cell of Fig. 8: EXP1 shows a stronger deep estuarine cell than EXP2, expecially on seasonal basis. We speculate the slow abyssal circulation of deep water masses in EXP1, as rivers riduce the SAd DW outflow to narrower bands, as well as the complex topography promote the diapycnal upwelling and result in a stronger abyssal estuarine cell.

\section{Conclusions and future developments}

In this paper we investigated the influence of river freshwater inflow on the vertical overturning cell of the Central Mediterranean Sea (CMOC). A twin experiment, with and without runoff, was carried out from the beginning of 1999 to the end of 2012. For EXP1 with 

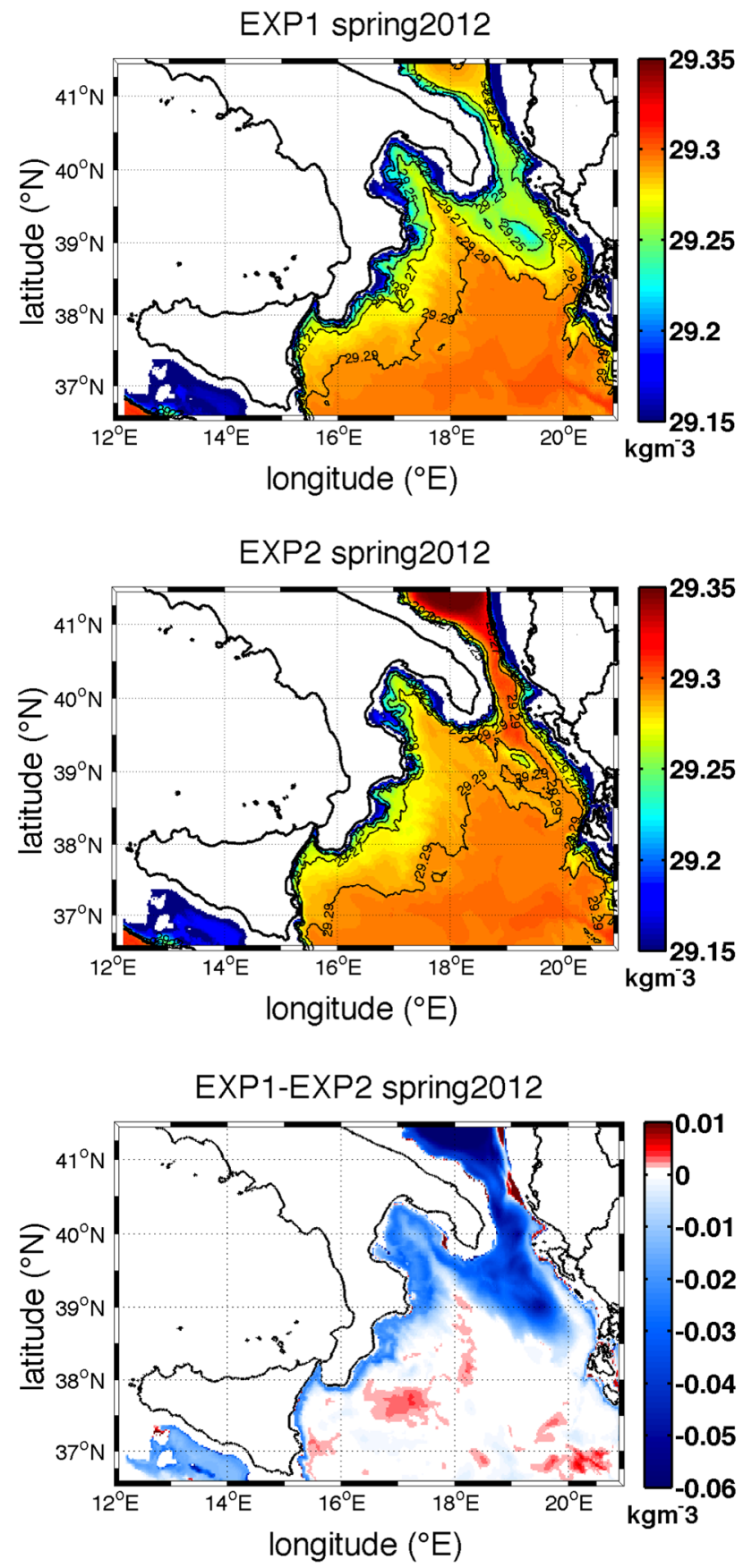

Fig. 16 Seasonal potential density anomaly on a $200 \mathrm{~m}$ layer above seabed and difference between EXP1 and EXP2 with zoom on the Ionian Sea

realistic runoff estimate, the comparison with satellite SST and ARGO profiles shows that the model is capable to reproduce the major characteristics of the observed water masses. We then take this experiment to be the best estimate of reality and we subtract the river runoff from the simulation and we study the differences between the two experiments. Our study is "mechanistic", i.e. we use a full forcing and dynamics simulation with a realistic estimate of river runoff and then we subtract the runoff to understand its impacts.

The anti-estuarine CMOC has its downwelling branch in the SAd deep water formation areas and thus we analyze first the marginal sea overturning circulation characteristics to understand differences due to runoff. We first compute the surface forcing budget and the theoretical marginal sea estuarine/antiestuarine parameters devised by Spall (2012). The long term and surface average of the buoyancy forcing over the Adriatic Sea is negative but during years of large runoff it changes sign, thus supporting the conjecture that the Adriatic Sea could change from anti-estuarine to estuarine vertical circulation. However the computation of Spall (2012) thermal and freshwater nondimensional parameters demonstrates that river runoff cannot reverse the dominant anti-estuarine character of Adriatic circulation or shut down the deep convection in the basin interior because the system is mainly in the thermal mode and wind work is always positive.

Our results for the realistic runoff case show that the multiannual CMOC for the decade 2000-2012 is a permanent anti-estuarine meridional overturning cell, occupying the Southern Adriatic and the Ionian Sea, plus secondary estuarine cells in the NAd and in the MAd, SAd deep layers as well as in the Northern Ionian abyss. The deep estuarine cell in the Ionian abyss is pointed out for the first time in this study and we speculate this is the result of diapycnal upwelling in the turbulent boundary layer close to the sloping bottom of the Ionian abyss.

A key result is that the CMOC is largely driven by wind work and heat fluxes but large and anomalous river runoff can affect its strength, enhancing the amplitude of the secondary estuarine cells and reducing the intensity of the dominant anti-estuarine cell.

Two additional experiments have been performed by enhancing the realistic runoff estimate of all rivers of $50 \%$ and $100 \%$. Both experiments show an abrupt reduction of the antiestuarine CMOC cell on multiannual basis: the antiestuarine cell does not disappear but strongly reduces its intensity and extends only in the Northern Ionian subbasin, while the deep estuarine cell of the Ionian abyss enlarges over the SAd.

We found that on 2001 the middle depth antiestuarine cell disappears with both realistic and augmented runoff, due to the weak wind work and the lowest heat budget. This means that rivers play a relevant role in the CMOC strength but they do not represent its dominant forcing mechanism and the potential role of river runoff on the intensity and direction of the CMOC has to be considered jointly with wind work and heat flux, as they largely contribute to the energy budget of the basin.

We focused on the downwelling branch of the Central Mediterranean MOC, which develops in the Adriatic basin 
due to dense water formation processes. Rivers are demonstrated to affect the Adriatic dense water volumes. Previous studies showed that rivers reduce the dense water formation in the Northern sub-region where most discharge is located. Here we show that rivers also directly affect the vertical mixing processes in the Southern Adriatic sub-region by changing the water column stratification in the SAd and thus decreasing the dense water volumes.

Finally we showed that the Adriatic dense waters overflowing the Otranto Strait are less dense in a realistic runoff regime and confined to a narrower band against the Italian shelf with less lateral spreading toward the Ionian Sea center.

Future investigations will point to an advanced implementation of river discharge in the model and the extension to the whole Mediterranean Sea. The next questions could consider the connection between the CMOC and the zonal overtuning cell of the Mediterranean Sea that supports the flow of LIW in the different deep water formation areas of the eastern and western Mediterranean Sea.

Acknowledgements We thank to the anonymous reviewers for their very useful comments and discussions.

Funding This work was funded by the Italian Project TESSA through Centro Euro-Mediterraneo sui Cambiamenti Climatici, Lecce, Italy. Nadia Pinardi was funded by the GEMINA Project at CMCC and Paolo Oddo by the RITMARE Project at INGV.

Open Access This article is distributed under the terms of the Creative Commons Attribution 4.0 International License (http:// creativecommons.org/licenses/by/4.0/), which permits unrestricted use, distribution, and reproduction in any medium, provided you give appropriate credit to the original author(s) and the source, provide a link to the Creative Commons license, and indicate if changes were made.

\section{Appendix 1: The numerical model configuration}

The numerical simulations were carried out using threedimensional, finite difference primitive equations Nucleus for European Modelling of the Ocean code, NEMO v 3.4 (Madec 2008).

The model solves prognostic equations for potential temperature, practical salinity, horizontal velocity components in the meridional and zonal directions, sea surface height and diagnostic equations for vertical velocity, hydrostatic pressure and potential density.

Boussinesq and hydrostatic hypotheses are assumed.

$$
\begin{aligned}
\frac{\partial u}{\partial t}+u \frac{\partial u}{\partial x}+v \frac{\partial u}{\partial y}+w \frac{\partial u}{\partial z}= & -\frac{1}{\rho_{0}} \frac{\partial p}{\partial x}+A_{m}\left(\frac{\partial^{2} u}{\partial x^{2}}+\frac{\partial^{2} u}{\partial y^{2}}\right) \\
& +K_{m} \frac{\partial^{2} u}{\partial z^{2}}+f v
\end{aligned}
$$

$\frac{\partial v}{\partial t}+u \frac{\partial v}{\partial x}+v \frac{\partial v}{\partial y}+w \frac{\partial v}{\partial z}=-\frac{1}{\rho_{0}} \frac{\partial p}{\partial y}+A_{m}\left(\frac{\partial^{2} v}{\partial x^{2}}+\frac{\partial^{2} v}{\partial y^{2}}\right)+K_{m} \frac{\partial^{2} v}{\partial z^{2}}-f u$

$\frac{\partial p}{\partial z}=-\rho g$

$\nabla \cdot \vec{u}=0$

$\frac{\partial \eta}{\partial t}+\nabla_{H} \cdot\left({\overrightarrow{u_{H} \text { baro }}}_{(H+\eta))}(H+R-E\right.$

$\frac{\partial S}{\partial t}+\nabla \cdot(\vec{u} S)=A_{t} \nabla_{H}^{2} S+K_{t} \frac{\partial^{2} S}{\partial z^{2}}$

$\frac{\partial \theta}{\partial t}+\nabla \cdot(\vec{u} \theta)=A_{t} \nabla_{H}^{2} \theta+K_{t} \frac{\partial^{2} \theta}{\partial z^{2}}$

$\rho=\rho(\theta, S, p)$

The first two Eqs. (3) and (4) are the Navier-Stokes equations with the Boussinesq approximation for the three dimensional horizontal velocity vector field $\overrightarrow{u_{H}}=(u, v)$ while Eq. (5) is the hydrostatic approximation of the vertical velocity component. The coefficients $A_{m}$ and $K_{m}$ are the momentum eddy coefficients for horizontal and vertical mixing respectively, $f v$ and $-f u$ are the horizontal components of Coriolis term. The Eq. (6) is the continuity equation with the incompressible approximation $\vec{u}=(u, v, w)$ which allows to compute the vertical velocity, $w$, as diagnostic variable. The Eq. (7) is the vertically integrated continuity equation, written as a prognostic equation for the free surface starting from the vertical integration of Eq. (6) and replacing the definition of barotropic velocity that is $\overrightarrow{u_{H} \text { baro }}=\frac{1}{\eta+H} \int_{-H}^{\eta} \overrightarrow{u_{H}} d z$.

The Eqs. (8) and (9) are the advection/diffusion equations for tracers with $A_{t}$ and $K_{t}$ the horizontal and vertical mixing coefficients of tracers.

Finally the sea state Eq. (10) prescribes the ocean water density as a non linear empirical function of potential temperature, salinity and pressure (following Jackett and McDougall 1995).

The sea surface height Eq. (7) and the associated barotropic velocity equations are solved by the time-splitting formulation, thus using a smaller time step than for threedimensional prognostic variables.

In order to solve the mesoscale variability of the Adriatic Sea, at least in the Southern sub-basin, a horizontal grid resolution equal to $1 / 45^{\circ}$ was chosen, corresponding to $2.47 \mathrm{~km}$ in the meridional direction and $1.72-2.13 \mathrm{~km}$ in the zonal direction. The literature shows the first baroclinic Rossby radius of deformation in the Mediterranean Sea is around 10-12 km (Grilli and Pinardi 1998; Pinardi and Masetti 2000) if we take the open flow scale 
variables, but the local values may significantly reduce depending on season and latitude and moving towards the shelf areas. In the Northern Adriatic Sea it reduces up to about $3-5 \mathrm{~km}$ in summer and $1 \mathrm{~km}$ in winter (Paschini et al. 1993; Masina and Pinardi 1994; Bergamasco et al. 1996). This means our model can explicitly resolve the mesoscale activities in the Adriatic Sea, at least in the Southern sub-basin, on seasonal as well as on interannual basis with the only exception of the Northern Adriatic where the model may result eddy-permitting but not eddy-resolving.

The model bathymetry, covering both the Adriatic and Ionia Sea, is taken from the US Navy $1 / 60^{\circ}$ bathymetric database DBDB1 using bilinear interpolation.

A total of 121 unevenly spaced z-levels with partial steps were adopted in the vertical direction. Partial steps allow a better representation of the bathymetry. The higher resolution in the top layers (23 levels in the top $35 \mathrm{~m}$ which is the mean depth of the NAd subregion) leads to an improved simulation of the bottom flow in the NAd and vertical mixing during higher stratification in the summer.

There are two open boundaries on the eastern and western sides of the model domain. Open boundaries data are provided as monthly means and involve the following prognostic variables interpolated on the model grid: zonal velocity $\left(u_{3 d}\right)$, meridional velocity $\left(v_{3 d}\right)$, potential temperature $(\theta)$, salinity $(\mathrm{S})$, and the sea surface height $(\eta)$.

For both the lateral open boundary conditions, LOBCs, and the initial conditions, ICs, data are taken from daily analysis of the operational Mediterranean forecasting System, MFS (Tonani et al. 2008; Oddo et al. 2009; Pinardi and Coppini 2010) based on the same code, NEMO, and covering the whole Mediterranean basin with $1 / 16$ horizontal resolution.

The numerical schemes adopted for the LOBCs are described below.

Marchesiello's algorithm (Marchesiello et al. 2001) was used for active tracers. It consists of the $2 \mathrm{D}$ radiation condition plus a relaxation/nudging term as follows:

$\frac{\partial \phi}{\partial t}+C_{\phi_{x}} \frac{\partial \phi}{\partial x}+C_{\phi_{y}} \frac{\partial \phi}{\partial y}=-\frac{1}{\tau}\left(\phi-\phi_{\text {nested }}\right)$

where $\varphi$ is the tracer $\left(\theta\right.$ or S), $\phi_{\text {nested }}$ is the coarser model (MFS) solution for the tracer interpolated on our model grid and provided monthly. The time scale for the nudging term, $\tau$, is constant and equal to 1 day for inward propagation and 15 days for outward propagation.

For outward propagation, i.e. $C_{\phi_{x}}>0$ where $C_{\phi_{x}}$ is the component of the phase velocity normal to the boundary, the tangential component is set equal to zero, $C_{\phi_{y}}=0$.
For inward propagation, $C_{\phi_{x}}<0$, the algorithm prescribes $C_{\phi_{x}}=C_{\phi_{y}}=0$ thus reduced to a relaxation condition.

For the horizontal velocity components, $u_{3 d}$ and $v_{3 d}$, the imposition scheme is used and thus, the incoming and outgoing information is totally determined by the coarser model data, irrespective of the inner solution.

In addition, the horizontal velocity component normal to each boundary is uniformly adjusted according to the "interpolation constraint" procedure (Pinardi et al. 2003) in order to preserve the total volume transport after data interpolation from the coarse to the fine resolution grid.

For the barotropic velocities, $u_{B T}$ and $v_{B T}$, Flather's scheme (1976) was adopted. The barotropic velocity component normal to the eastern and western boundaries is given by Flather's equation:

$u_{B T}=u_{B T_{\text {nested }}}-\frac{\sqrt{g H}}{H}\left(\eta_{\text {nested }}-\eta\right)$

where $\eta_{\text {nested }}$ is the coarser model sea surface height at the boundary interpolated over the finer model grid, $\eta$ is the finer model sea surface height at the boundary and $u_{B T_{\text {nested }}}$ is the coarser model normal barotropic velocity over the finer model grid computed as

$u_{B T_{\text {nested }}}=\frac{1}{H+\eta} \int_{-H}^{\eta} u_{3 d_{\text {nested }}} d z$

The tangential barotropic velocity is set equal to zero: $v_{B T}=0$.

In Flather's formula, $\eta$ values at the boundary follow a "zero gradient boundary condition" which means $\eta_{B}=\eta_{B-1}$ (subscript B stands for boundary line values). This avoids numerical instabilities.

The bottom boundary condition is applied only on momentum and consists of a quadratic friction.

No slip boundary conditions are adopted along the coastline for tangential velocity.

In order to define the air-sea interaction, the vertical fluxes of momentum, heat and salt and the vertical velocity were parameterized at the sea surface. These parameterizations are the surface boundary conditions (SBCs) of the model. Wind stress and heat flux components are computed by means of "bulk formulae" (Castellari et al. 1998; Maggiore et al. 1998; Oddo and Guarnieri 2011; Madec 2008) using atmospheric data provided by the European Centre for Medium Weather Forecasts (ECMWF). These atmospheric data ( $2 \mathrm{~m}$ air temperature, $2 \mathrm{~m}$ dew point temperature, total cloud cover, mean sea level atmospheric pressure, meridional and zonal $10 \mathrm{~m}$ wind components) are operational analyses with a $6 \mathrm{~h}$ frequency and with $0.5^{\circ}$ horizontal resolution up to 2008 and $0.25^{\circ}$ thereafter. It should be noted that the increase in spatial 
resolution of the ECMWF fields could lead to a spurious increase of the wind stress magnitude.

Only the precipitation rate $(\mathrm{P})$ data are extracted from the CMAP (CPC, Climate Prediction Center, Merged Analysis of Precipitation) monthly data set with a horizontal resolution of $2.5^{\circ} \times 2.5^{\circ}$. This coarse precipitation data set is a weakness of our model formulation but precipitation data set from ECMWF was still too poor for the first decade of the XXI century (Haiden et al. 2015) and this would have offset the buoyancy budget in an unphysical manner.

The surface boundary condition for temperature involves a balance between solar short-wave radiation $Q_{s}$ (computed using Reed's formula, 1977), long-wave radiation $Q_{l}$ (computed using Bignami et al. 1995), latent $Q_{e}$ and sensible $Q_{h}$ heat fluxes [by means of bulk formulae proposed by Kondo (1975)].

Reed's formula is:

$Q_{s}=Q_{t o t}(1-0.62 C+0.0019 \beta)(1-\alpha)$

where $\mathrm{Q}_{\text {tot }}$ is the clear-sky radiation, $C$ is the fractional cloud cover, $\beta$ is the noon sun altitude in degrees, and $\alpha$ is the sea surface albedo. The albedo is computed as a function of the sun zenith angle for each grid point from Payne (1972).

The Bignami formula is:

$$
Q_{l}=\epsilon \sigma T_{S}^{4}-\left[\sigma T_{A}^{4}\left(0.653+0.00535 e_{A}\right)\right]\left(1+0.1762 C^{2}\right)
$$

where $\epsilon$ is the ocean emissivity, $\sigma$ is the Stefan Boltzmann constant, $e_{A}$ is the atmospheric vapor pressure, $T_{S}$ is the sea surface temperature predicted by model, $T_{A}$ is the $2 \mathrm{~m}$-air temperature.

The sensible $Q_{h}$ and latent $Q_{e}$ heat fluxes are parameterized through the Kondo bulk formula:

$Q_{h}=\rho_{A} C_{p} C_{H}|v|\left(T_{S}-T_{A}\right)$

$Q_{e}=\rho_{A} L_{e} C_{E}|v|\left[e_{\text {sat }}\left(T_{S}\right)-r e_{s a t} T_{A}\right]\left(0.622 / p_{A}\right)$

where $\rho_{A}=\rho_{A}\left(p, T_{A}, r\right)$ is moist air density, $\mathrm{r}$ is the relative umidity, $C_{p}$ is the specific heat capacity at constant pressure, $C_{H}$ and $C_{E}$ are the turbulent exchange coefficients computed according to Kondo (1975), $L_{e}$ is the latent heat of vaporization, $e_{\text {sat }}$ is the vapor pressure, $|v|$ is the wind speed modulus, and $p_{A}$ is the atmospheric pressure.

For the heat flux boundary condition at the surface, we assume:

$\left.\rho_{0} K_{t} \frac{\partial \theta}{\partial z}\right|_{z=\eta}=\frac{1}{C_{p}}\left[\left(1-T_{r}\right)\left(Q_{s}-Q_{l}-Q_{h}-Q_{e}\right)\right]$

where $T_{r}$ is the Jerlov (1976) transmission coefficient for a "clear" water type and $K_{t}$ is the vertical mixing coefficient for traces.
The wind stress involved in the surface boundary condition for momentum is calculated from the relative winds with the formula:

$\mathrm{T}_{w}=\rho_{0 a} C_{D}\left|U_{r e l}\right| U_{r e l}$

where $U_{r e l}=u_{w}-u_{s}=\left(u_{r e l}, v_{r e l}\right)$ is the relative wind field that is the $10 \mathrm{~m}$ wind horizontal velocity $u_{w}$ subtracted from the sea surface horizontal velocity $u_{S}, \rho_{0 a}$ is the density of the moist air and $C_{D}\left(T_{a}, T_{s}, u_{w}\right)$ is the drag coefficient which depends on air temperature, sea surface temperature and wind amplitude according to Hellerman and Rosenstein (1983).

The momentum boundary condition at the surface is:

$\left.\rho_{0} K_{m} \frac{\partial(u, v)}{\partial z}\right|_{z=\eta}=\left(\tau_{w x}, \tau_{w y}\right)$

where $\tau_{w x}=\rho_{0 a} C_{D}\left|U_{r e l}\right| u_{r e l}$ and $\tau_{w y}=\rho_{0 a} C_{D}\left|U_{r e l}\right| v_{r e l}$ are the wind stress components and $K_{m}$ is the vertical mixing coefficient for momentum.

The freshwater balance defined as evaporation minus precipitation and runoff (with the latter divided by the cell area of the river mouth), E-P-R/A, is directly involved in the surface boundary conditions for salinity and for vertical velocity. The evaporation rate $(\mathrm{E})$ is calculated by the latent heat flux according to $E=\frac{Q_{e}}{L_{e}}$.

The salinity boundary condition at the surface reads:

$\left.K_{t} \frac{\partial S}{\partial z}\right|_{z=\eta}=S_{z=\eta}(E-P-R / A)$

where $\eta$ is the sea surface elevation and $S_{z=\eta}$ is the ocean model surface salinity except prescribed ad-hoc salt values at river mouths.

The surface boundary condition for the vertical velocity is as follows:

$\left.w\right|_{z=\eta}-\frac{\partial \eta}{\partial t}-\left.u\right|_{z=\eta} \cdot \nabla_{H} \eta=(E-P-R / A)$

where $w$ is the vertical velocity.

With regard to the dynamics, the following choices were selected: vector invariant form for momentum advection, bi-Laplacian operator for lateral diffusion and horizontal eddy viscosity coefficient equal $-5 \times 10^{7} \mathrm{~m}^{4} \mathrm{~s}^{-1}$ according to a tuning procedure starting with MFS values, implicit vertical diffusion and TKE turbulence closure scheme (Mellor and Blumberg 2004) to provide the vertical eddy coefficients.

With regard to the active tracers: MUSCL advection scheme, bi-Laplacian operator for lateral diffusion and horizontal eddy diffusivity coefficient equal to $-3 \times 10^{7} \mathrm{~m}^{4} \mathrm{~s}^{-1}$ according to a tuning procedure, implicit and TKE dependent vertical diffusion. 


\section{Appendix 2: The computation of Spall parameters for semi-enclosed seas}

Following Spall's studies $(2004,2010,2011,2012)$ on overturning circulation in marginal seas, we computed two non-dimensional coefficients which represent the relative balance between heat and freshwater budget in the interior of the Adriatic Sea due to air-sea interaction and the lateral eddy fluxes that advect warm and salty water in the basin interior and are detach from the cyclonic boundary current which inflows along the eastern side from the open ocean and encircles the marginal sea.

The combinations $\mu / \varepsilon$ and $\gamma / \varepsilon$ are called respectively thermal and freshwater forcing parameter and are described below:

$\frac{\mu}{\varepsilon}=\frac{A \Gamma f_{0}}{\alpha_{T} G C_{p} H^{2} T^{*}} / \frac{c P}{L}$

$\frac{\gamma}{\varepsilon}=\frac{8 A \rho_{0} f_{0} S_{0} \alpha_{S}(E-P-R)}{g H^{2} \alpha_{T}^{2} T^{* 2}} / \frac{c P}{L}$

where $A$ is the area of the Adriatic sea surface (from model domain), $\boldsymbol{\Gamma}$ is the relaxation constant for the basin sea surface temperature toward the atmospheric temperature (from Spall 2011), $f_{0}$ is the Coriolis parameter, $\alpha_{T}$ is the thermal expansion coefficient (from Cessi et al. 2014), $\alpha_{S}$ is the haline expansion coefficient (from Cessi et al. 2014), $H$ is the depth of the sill (from model domain), $P$ is the perimeter of the basin interior (from model domain), $c_{P}$ is the thermal capacity (from Cessi et al. 2014), $L$ is the $L$ is the width of the sloping topography over which the inflowing boundary current lies (thus computed from model results as the cross-shore width of the inflowing boundary current along the eastern shelf of the Adriatic basin).

The variable $\delta=\frac{h_{x}}{-\bar{\rho}_{x} / \bar{\rho}_{z}}=-0.33$ represents the topography slope over the mean isopycnal slope in the boundary current, thus both computed along the Southern Adriatic eastern shelf (x-direction stands for zonal direction and $\mathrm{z}$ means depth). To note that $\delta$ has been computed by considering a zonal transect of potential density anomaly at $40.8^{\circ} \mathrm{N}$ (so just north of the Otranto Strait) on annual basis and focusing on the eastern side of the basin. For cyclonic boundary current, $\delta<0$ and the topography acts to stabilize the boundary current and reduce the amount of lateral eddy flux into the interior. The quantity $\boldsymbol{c}=0.025 e^{2 \delta}=0.05$ is an efficiency coefficient that depends on the bottom slope and regulates the eddy heat flux from the boundary current into the interior (Spall 2004).
The non-dimensional parameter $\varepsilon=c P / L$ is the ratio of the heat flux toward the basin interior due to lateral eddies compared to that advected into the Adriatic Sea through the inflowing boundary current along the Southern Adriatic eastern shelf. The inflowing boundary current is assumed to be a geostrophic current in thermal wind balance. The value of $\varepsilon$ is very small for stable boundary currents and increases for boundary currents that are sufficiently unstable that they lose all their heat to the interior of the basin before it is carried all the way around the marginal sea.

Moreover the thermal and freshwater forcing parameters required to compute $T^{*}$, that is the difference between the inflowing temperature and the temperature of the atmosphere over the interior of the marginal sea, as follows :

$T^{*}=T_{1}-T_{A}= \begin{cases}2.56\left({ }^{\circ} \mathrm{C}\right) & \text { in } E X P 1 \\ 2.84\left({ }^{\circ} \mathrm{C}\right) & \text { in EXP2 }\end{cases}$

where $T_{1}$ is the mean temperature of the inflowing current along the eastern boundary derived from the EXPs, $T_{A}$ is the mean $2 \mathrm{~m}$ temperature over the Adriatic basin extracted from ECMWF $25 \mathrm{~km}$ dataset.

Finally the surface freshwater flux is defined as follows:

$E-P=0.66 \times 10^{-7}\left(\mathrm{~ms}^{-1}\right)$ in $E X P 2$

$E-P-R=-2.18 \times 10^{-7}\left(\mathrm{~ms}^{-1}\right)$ in EXP1

All the quantities described above enable to compute the thermal and freshwater forcing parameters in Eqs. (22) and (23), giving:

$\mu / \varepsilon=\left\{\begin{array}{lll}5.0 \times 10^{-5} & \text { in } & E X P 1 \\ 4.9 \times 10^{-5} & \text { in } & E X P 2\end{array}\right.$

$\gamma / \varepsilon=\left\{\begin{array}{l}-2.0 \times 10^{-2} \text { in EXP1 } \\ 7 \times 10^{-4} \text { in } \operatorname{EXP} 2\end{array}\right.$

As discussed by Spall (2011), $\mu / \varepsilon$ is a measure of the relative influence of lateral eddy heat fluxes from the boundary current into the basin interior compared to heat loss to the atmosphere. For $\mu / \varepsilon \ll 1$, lateral eddy heat flux from the boundary is very strong and leads to a relatively warm basin interior so that $T \approx T_{1}$, if $\mu / \varepsilon>1$ the boundary current is relatively stable and the atmosphere is able to strongly cool the basin interior so that $T \approx T_{A}$. Similarly $\gamma / \varepsilon$ describes the relative role of surface forcing and lateral eddy fluxes in the salinity balance. Large values of $\gamma / \varepsilon$ indicate dominance of atmospheric forcing implying freshwater gains in the basin interior that are not balanced by lateral eddy fluxes of salt from the boudary current, and small values indicate strong lateral eddy fluxes.

In order to evaluate the shutdown of deep convection and the reversal of the overturning circulation, the temperature and salinity anomalies of the basin convective 
Table 3 Summary of the key parameters of the Twin experiment

\begin{tabular}{lll}
\hline Parameter & EXP1 & EXP2 \\
\hline$\mu / \varepsilon$ & $5.0 \times 10^{-5}$ & $4.9 \times 10^{-5}$ \\
$\gamma / \varepsilon$ & $-2 \times 10^{-2}$ & $+7 \times 10^{-4}$ \\
$\Delta T$ & 0.35 & 0.28 \\
$\Delta S$ & 0.10 & 0.03 \\
$\Delta S / \Delta T$ & 0.28 & 0.12 \\
\hline
\end{tabular}

The model-diagnosed quantities are the thermal forcing parameter $\mu / \varepsilon$, the freshwater forcing parameter $\gamma / \varepsilon$, the temperature anomaly of the convective water mass $\Delta T$ and the salinity anomaly of the convective water mass $\Delta S$

water mass have been computed as normalized differences of $\mathrm{T}$ (i.e. $\Delta T$ ) and $\mathrm{S}$ (i.e. $\Delta S$ ) between basin interior and boundary currents (Spall 2012).

A set of two non-dimensional equations has been derived to compute $\Delta T$ and $\Delta S$ (Spall 2012), these equations include the non-dimensional parameters $\mu / \varepsilon$ and $\gamma / \varepsilon$ and describe $\Delta T$ and $\Delta S$ as function of basin geometry, atmospheric forcing and lateral eddy fluxes.

The simplified formula suggested in Spall (2012) are:

$\Delta T=T_{1}-T / T^{*}$

$\Delta S=\left(S_{1}-S\right) \alpha_{S} / \alpha_{T} T^{*}$

where $T$ and $S$ for the basin interior and $T_{1}$ and $S_{1}$ for the inflowing current have been computed over 50-200 m depth.

The ratio $\Delta S / \Delta T<1$ means the stable circulation state is in the "Thermal mode" with surface heat losses and freshwater gains prevailing the lateral eddy advection of warm and salt water in the basin interior (thermal and freshwater forcing coefficients are significantly high). In this case the density contrast is dominated by the temperature difference and the water in the interior of the marginal sea is more dense than that in the boundary current.

If $\Delta S / \Delta T>1$, the stable circulation state is in the "Haline mode" with surface heat and freshwater budget of the interios basin favoring the lateral eddy advection of warm and salt water (thermal and freshwater forcing coefficients are low enough and the latter is eventually negative). In this case the density contrast is dominated by the salinity difference and the water in the interior of the marginal sea is less dense than that in the boundary current. Thus the boundary corrent detaches from the eastern shelf and spreads in the interior basin. This means in haline mode the surface boundary current is in the opposite sense, anticyclonic around the coastline, and the deep convection in the basin interior is not longer supported with reversal of the meridional overturning circulation.
The theoretical limit for shutdown of deep convection is $\Delta S / \Delta T \geqslant 0.5$, thus possible also in the thermal mode.

According to our findings, both EXPs are in the thermal mode and EXP1 is closer to the threshold limit for shutdown of deep convection than EXP2.

Results collected for EXP1 and EXP2 are summarizes in Table 3 and show that deep convection in the Southern Adriatic, surface cyclonic boundary current and anti-estuarine overturning circulation of the Adriatic basin characterize both experiments but in EXP1, with a realistic parameterization of river runoff, the freshwater forcing coefficient is negative and the ratio $\Delta S / \Delta T$ close to 0.5 . This corroborates strong river discharge in the Adriatic Sea has the potential to trigger the shutdown of deep convection and the weakening of the anti-estuarine overturning circulation.

\section{References}

Amitai Y, Ashkenazy Y, Gildor H (2016) Multiple equilibria and overturning variability of the Aegean-Adriatic Seas. Glob Planet Change

Artegiani A, Azzolini R, Salusti E (1989) On the dense water in the Adriatic Sea. Oceanol Acta 12:151-160

Artegiani A, Paschini E, Russo A, Bregant D, Raicich F, Pinardi N (1997a) The Adriatic Sea general circulation. Part I: airsea interactions and water mass structure. J Phys Ocean 27:1492-1514

Artegiani A, Paschini E, Russo A, Bregant D, Raicich F, Pinardi N (1997b) The Adriatic Sea general circulation. Part II: baroclinic circulation structure. J Phys Ocean 27:1515-1532

Bensi M, Rubino A, Cardin V, Hainbucher D, Mancero-Mosquera I (2013a) Structure and variability of the abyssal water masses in the Ionian Sea in the period 2003-2010. J Geophys Res Oceans 118(2):931-943

Bensi M, Cardin V, Rubino A, Notarstefano G, Poulain PM (2013b) Effects of winter convection on the deep layer of the Southern Adriatic Sea in 2012. J Geophys Res Oceans 118(11):6064-6075

Bergamasco A, Gacic M, Boscolo R, Umgiesser G (1996) Winter oceanographic conditions and water mass balance in the Northern Adriatic (February 1993). J Mar Sys 7:67-94

Bethoux JP (1979) Budgets of the Mediterranean Sea: their dependence on the local climate and on the characteristics of the Atlantic waters. Oceanol Acta 2:157-163

Beuvier J, Sevault F, Herrmann M, Kontoyiannis H, Ludwig W, Rixen M, Stanev E, Béranger K, Somot S (2010) Modelling the Mediterranean Sea interannual variability over the last 40 years: focus on the EMT. JGR-Ocean 115(C8):1978-2012

Bignami F, Marullo S, Santoleri R, Schiano ME (1995) Longwave radiation budget in the Mediterranean Sea. J Geophys Res 100(C2):2501-2514

Budillon G, Bue NL, Siena G, Spezie G (2010) Hydrographic characteristics of water masses and circulation in the Northern Ionian Sea. Deep Sea Res Top Stud Oceanogr 57:441-457

Cardin V, Bensi M, Pacciaroni M (2011) Variability of water mass properties in the last two decades in the South Adriatic Sea with emphasis on the period 2006-2009. Cont Shelf Res 31(9):951-965 
Castellari S, Pinardi N, Leaman K (1998) A model study of air-sea interactions in the Mediterranean Sea. J Mar Syst 18(1-3):89-114

Cessi P, Pinardi N, Lyubartsev V (2014) Energetics of semienclosed basins with two-layer flows at the strait. J Phys Oceanogr 44(3):967-979

Curchitser EN, Haidvogel DB, Iskandarani M (2001) Transient adjustment of circulation in a midlatitude Abyssal Ocean basin with realistic geometry and bathymetry. J Phys Oceanogr 31:725-745

Cushman-Roisin B, Gacić M, Poulain P-M, Artegiani A, 2002. Physical oceanography of the Adriatic Sea: past, present and future. Kluwer Academic Publishers, pp 304

De Lavergne C, Madec G, Le Sommer J, Nurser AG, Naveira Garabato AC (2016) The impact of a variable mixing efficiency on the abyssal overturning. J Phys Oceanogr 46(2):663-681

Dell'Aquila A, Calmanti S, Ruti P, Struglia MV, Pisacane G, Carillo A, Sannino G (2012) Effects of seasonal cycle fluctuations in an A1B scenario over the Euro-Mediterranean region. Clim Res 2:135

Federico I, Pinardi N, Coppini G, Oddo P, Lecci R, Mossa M (2016) Coastal ocean forecasting with an unstructured-grid model in the Southern Adriatic Northern Ionian Sea. Nat Hazards Earth Syst Sci Discuss. doi:10.5194/nhess-2016-169

Ferrari R, Mashayek A, McDougall TJ, Nikurashin M, Campin JM (2016) Turning ocean mixing upside down. J Phys Oceanogr

Flather RA (1976) A tidal model of the northwest European continental shelf. Memories de la Societe Royale des Sciences de Liege 6(10):141-164

Gacic' M, Eusebi Borzelli GL, Civitarese G, Cardin V, Yari S (2010) Can internal processes sustain reversals of the ocean upper circulation?, The Ionian Sea example. Geophys Res Lett 37:L09608

Gacic' M, Civitarese G, Borzelli, G.L.E., Kovacevic V, Poulain PM, Theocharis A, Menna M, Catucci A, Zarokanellos N (2011) On the relationship between the decadal oscillations of the northern Ionian Sea and the salinity distributions in the eastern Mediterranean. J Geophys Res 116-125

Gertman I, Pinardi N, Popov Y, Hecht A (2006) Aegean Sea water masses during the early stages of the Eastern Mediterranean climatic transient (1988-90). J Phys Oceanogr 36(9):1841-1859

Grilli F, Pinardi N (1998) The computation of Rossby radii of deformation for the Mediterranean Sea. MTP News

Guarnieri A, Pinardi N, Oddo P, Bortoluzzi G, Ravaioli M (2013) Impact of tides in a baroclinic circulation model of the Adriatic Sea. J Geophys Res Oceans 118(1):166-183

Gunduz M, Dobricic S, Oddo P, Pinardi N (2013) Impact of Levantine Intermediate Water on the interannual variability of the Adriatic Sea based on simulations with a fine resolution ocean model. Ocean Model 72:253-263

Haiden T, Janousek M, Bauer P, Bidlot J, Dahoui M, Ferranti L, Hewson T, Prates F, Richardson DS, Vitart F (2015) Evaluation of ECMWF forecasts, including 2014-2015 upgrades. Technical report 765 . ECMWF

Hainbucher D, Rubino A, Klein B (2006) Water mass characteristics in the deep layers of the western Ionian Basin observed during May 2003. Geophys Res Lett 33:4

Hellerman S, Rosenstein M (1983) Normal monthly wind stress over the world ocean with error estimates. J Phys Oceanogr 13:1093-1104

Huang RX (1993) Real freshwater flux as a natural boundary condition for the salinity balance and thermohaline circulation forced by evaporation and precipitation. J Phys Oceanogr 23(11):2428-2446
Jackett DR, McDougall TJ (1995) Minimal adjustment of hydrographic data to achieve static stability. J Atmos Ocean Tech 12:381-389

Janeković I, Mihanović H, Vilibić I, Tudor M (2014) Extreme cooling and dense water formation estimates in open and coastal regions of the Adriatic Sea during the winter of 2012. J Geophys Res Oceans 119(5):3200-3218

Jerlov N (1976) Marine Optics. Elsevier Science Publishing Company

Kassis D, Konstantinidou A, Perivoliotis L, Korres G (2016) Intercomparing numerical model simulations in the Ionian Sea with Argo T/S profiles for the period 2008-2012

Killworth PD (2006) Time interpolation of forcing fields in ocean models. J Phys Oceanogr 26:136-143

Kondo J (1975) Air-sea bulk transfer coefficients in diabatic conditions. Bound-Layer Meteor 9:91-112

Knudsen M (1900) Ein hydrographischer Lehrsatz. Ann Hydrogr Maritimen Meteor 28:316-320

Kourafalou VH, Oey L-Y, Wang JD, Lee TL (1996) The fate of river discharge on the continental shelf. 1. Modeling the river plume and the inner shelf coastal current. J Geophys Res 101:3415-3434

Lascaratos A (1993) Estimation of deep and intermediate water mass formation rates in the Mediterranean Sea. Deep Sea Res Part II Topical Stud Oceanogr 40(6):1327-1332

Ludwig W, Dumont E, Meybeck M, Heussner S (2009) River discharges of water and nutrients to the Mediterranean and Black Sea: major drivers for ecosystem changes during past and future decades. Prog Oceanogr 80:199-217

Madec G (2008) NEMO ocean engine. Note du Pole de modélisation, vol 27. Institut Pierre-Simon Laplace (IPSL), France, pp 1288-1619

Maggiore A, Zavatarelli M, Angelucci MG, Pinardi N (1998) Surface heat and water fluxes in the Adriatic Sea: seasonal and interannual variability. Phys Chem Earth 23(5-6):561-567

Malacic V, Petelin B (2009) Climatic circulation in the Gulf of Trieste (northern Adriatic). J Geophys Res 114(C7)

Malanotte-Rizzoli P, Manca BB, Ribera d'Alcala' M, Theocharis A (1997) A synthesis of the Ionian Sea hydrography, circulation and water mass pathways during POEM-Phase I. Prog Ocean 39:153-204

Manca B, Kovaĉević V, Gaĉić M, Viezzoli D (2002) Dense water formation in the Southern Adriatic Sea and spreading into the Ionian Sea in the period 1997-1999. J Mar Syst 33-34:133-154

Manca B, Budillon G, Scarazzato P, Orsella L (2003) Evolution of dynamics in the Eastern Mediterranean affecting water mass structures and properties in the Ionian and Adriatic Seas. J Geophys Res 108(C9):101029-101046

Mantziafou A, Lascaratos A (2004) An eddy resolving numerical study of the general circulation and deep-water formation in the Adriatic Sea. Deep Sea Res Part I Oceanogr Res Pap Hist Med Assoc 51(7):921-952

Mantziafou A, Lascaratos A (2008) Deep-water formation in the Adriatic Sea: Interannual simulation for years 1979-1999. Deep Sea Res Part I Oceanogr Res Pap Hist Med Assoc 55(11):1403-1427

Marchesiello P, Williams JM, Shchepetkin A (2001) Open boundary conditions for long-term integrations of regional oceanic models. Ocean Model 3(1-2):1-20

Marshall J, Speer K (2012) Closure of the meridional overturning circulation through Southern Ocean upwelling. Nat Geosci 5(3): $171-180$

Masina S, Pinardi N (1994) Mesoscale data assimilation studies in the middle Adriatic Sea. Cont Shelf Res 14(12):1293-1310

Medhycos (2001) The Mediterranean hydrological cycle observing system. Medhycos phase II, period 2002-2005, report no. 17, pp 36 
Mellor G, Blumberg A (2004) Wave breaking and ocean surface layer thermal response. J Phys Oceanogr 34(3):693-698

Mihanovic H, Vilibic I, Carniel S, Tudor M, Russo A, Bergamasco A, Bubic N, Ljubesic Z, Vilicic D, Boldrin A, Malacic V (2013) Exceptional dense water formation on the Adriatic shelf in the winter of 2012. Ocean Sci 9:561-572

Milliman JD (2001) Delivery and fate of fluvial water and sediment to the sea: a marine geologist's view of European rivers. Sci Marina 65(Suppl 2):121-132

Munk W, Wunsch C (1998) Abyssal recipes II. Energetics of tidal and wind mixing. Deep Sea Res Part I Oceanogr Res Pap Hist Med Assoc 45(12): 1977-2010

Nikurashin M, Vallis G (2011) A theory of deep stratification and overturning circulation in the ocean. J Phys Oceanogr 41(3):485-502

Oddo P, Guarnieri A (2011) A Study of the hydrographic conditions in the Adriatic Sea from numerical modelling and direct observations (2000-2008). Ocean Sci 7:549-567

Oddo P, Pinardi N, Zavatarelli M (2005) A numerical study of the interannual variability of the Adriatic Sea (2000-2002). Sci Total Environ 353(1):39-56

Oddo P, Adani M, Pinardi N, Fratianni C, Tonani M, Pettenuzzo D (2009) A nested Atlantic-Mediterranean Sea general circulation model for operational forecasting. Ocean Sci

Paparella F, Young WR (2002) Horizontal convection is non-turbulent. J Fluid Mech 466:214

Pasaric M (2004) Annual cycle of river discharge along the Adriatic coast of Croatia. Rapports et procès-verbaux des reunions CIESMM 37:132

Paschini E, Artegiani A, Pinardi N (1993) The mesoscale eddy field of the middle Adriatic Sea during fall 1988. Deep Sea Res Part I Oceanogr Res Pap Hist Med Assoc 40(7):1365-1377

Payne RE (1972) Albedo of the sea surface. J Atmos Sci 29:959-970

Pedlosky J (1987) Geophysical fluid dynamics. Springer, Berlin, pp 724

Pettenuzzo D, Large W, Pinardi N (2010) On the corrections of ERA40 surface flux products consistent with the Mediterranean heat and water budgets and the connection between basin surface total heat flux and NAO. J Geophys Res 115:C06022

Pickard GL, Emery WJ (1982) Descriptive physical oceanography: an introduction, 4th edn. Pergamon Press, Oxford, pp 265

Pinardi N, Coppini G (2010) Operational oceanography in the Mediterranean Sea: the second stage of development. Ocean Sci 6:263-267

Pinardi N, Masetti E (2000) Variability of the large scale general circulation of the Mediterranean Sea from observations and modelling: a review. Palaeogeogr Palaeoclimatol Palaeoecol 158(3):153-173

Pinardi N, Allen I, Demirov E, De Mey P, Korres G, Lascaratos A, Le Traon PY, Maillard C, Manzella G, Tziavos C (2003) The Mediterranean ocean forecasting system: first phase of implementation (1998-2001). Ann Geophys 21(1):3-20

Pinardi N, Arneri E, Crise A, Ravaioli M, Zavatarelli M (2006) The physical, sedimentary and ecological structure and variability of shelf areas in the Mediterranean Sea. Sea 14:1243-1330

Pinardi N, Zavatarelli M, Adani M, Coppini G, Fratianni C, Oddo P, Tonani M, Lyubartsev V, Dobricic S, Bonaduce A (2015) Mediterranean Sea large-scale low frequency ocean variability and water mass formation rates from 1987 to 2007: a retrospective analysis. Prog Oceanogr 132:318-332

Pisacane G, Artale V, Calmanti S, Rupolo V (2006) Decadal oscillations in the Mediterranean Sea: a rFeesult of the overturning circulation variability in the eastern basin? Clim Res 31:257-271

Pisano A, Nardelli BB, Tronconi C, Santoleri R (2016) The new Mediterranean optimally interpolated pathfinder AVHRR SST dataset (1982-2012). Remote Sens Environ 176:107-116
Provini A, Crosa G, Marchetti R (1992) Nutrient export from Po and Adige river basins over the last 20 years. Sci Total Environ Suppl:291-313

Rahmstorf S (1995) Bifurcations of the Atlantic thermohaline circulation in response to changes in the hydrological cycle. Nature 378:145-149

Rahmstorf S (1996) On the freshwater forcing and transport of the Atlantic thermohaline circulation. Clim Dyn 12(12):799-811

Raicich F (1996) Note on the flow rates of the Adriatic rivers. Tech. Rep. RF 02/94. CNR, Istituto Talassografico di Trieste, Italy, p 8

Robinson AR, Leslie WG, Theocharis A, Lascaratos A (2001) Mediterranean sea circulation. Ocean Curr, 1689-1705

Roether W, Manca BB, Klein B, Bregant D, Georgopoulos D, Beitzel V, Kovacevic V, Luchetta A (1996) Recent changes in eastern Mediterranean deep waters. Science 271:333-335

Roussenov VM, Williams RG, Roether W (2001) Comparing the overflow of dense water in isopycnic and cartesian models with tracer observations in the eastern Mediterranean. Deep Sea Res Part I Oceanogr Res Pap Hist Med Assoc 48(5):1255-1277

Rubino A, Hainbucher D (2007) A large abrupt change in the abyssal water masses of the eastern Mediterranean. Geophys Res Lett. doi:10.1029/2007GL031737

Rubino A, Romanenkov D, Zanchettin D, Cardin V, Hainbucher D, Bensi M, Boldrin A, Langone L, Miserocchi S, Turchetto M (2012) On the descent of dense water on a complex canyon system in the southern Adriatic basin. Cont Shelf Res 44:20-29

Sanchez-Gomez E, Somot S, Josey SA, Dubois C, Elguindi N, Déqué M (2011) Evaluation of the Mediterranean Sea water and heat budgets as simulated by an ensemble of high resolution regional climate models. Clim Dyn 37:2067-2086

Schroeder K, Garcìa-Lafuente J, Josey S, Artale V, BuongiornoNardelli B, Gacic M, Gasparini GP, Herrmann M, Lionello P, Ludwig W, Millot C, Ozsoy E, Pisacane G, Sanchez-Garrido JC, Sannino G, Santoleri R, Somot S, Struglia M, Stanev E, Taupier-Letage I, Tsimplis M, Vargas-Yanez M, Zervakis V, Zodiatis G (2012) Circulation of the Mediterranean Sea and its variability (Chap. 4). In: Lionello P (ed) Mediterranean climate variability. Elsevier, Amsterdam, pp 187-256

Simoncelli S, Pinardi N, Oddo P, Mariano AJ, Montanari G, Rinaldi A, Deserti M (2011) Coastal rapid environmental assessment in the Northern Adriatic Sea. Dyn Atmos Oceans 52(1-2):250-283

Skliris N, Sofianos S, Lascaratos A (2007) Hydrological changes in the Mediterranean Sea in relation to changes in the freshwater budget: a numerical modelling study. J Mar Syst 65:400-416

Spall MA (2004) Boundary currents and water mass transformation in marginal seas. J Phys Oceanogr 34:1197-1213

Spall MA (2010) Dynamics of downwelling in an eddy-resolving convective basin. J Phys Oceanogr 40:2341-2347

Spall MA (2011) On the role of eddies and surface forcing in the heat transport and overturning circulation in marginal sea. J Mar Res 24:4844-4858

Spall MA (2012) Influences of precipitation on water mass transformation and deep convection. J Phys Ocean 42:1684-1700. doi:10.1175/jpo-d-11-0230.1

Struglia MV, Mariotti A, Filograsso A (2004) River discharge into the Mediterranean Sea: climatology and aspects of the observed variability. J Clim 17:4740-4751

Sverdrup HU (1947) Wind-driven currents in a baroclinic ocean; with application to the equatorial currents of the eastern Pacific. Proc Natl Acad Sci 33:318-326

Tonani M, Pinardi N, Dobricic S, Pujol I, Fratianni C (2008) A highresolution free surface model of the Mediterranean Sea. Ocean Sci 4(1):1-14 
Ursella L, Kovacevic V, Gacic M (2011) Footprints of mesoscale eddy passages in the Strait of Otranto (Adriatic Sea). J Geopys Res 116:14

Vervatis VD, Sofianos SS, Skliris N, Somot S, Lascaratos A, Rixen M (2013) Mechanisms controlling the thermohaline circulation pattern variability in the Aegean-Levantine region. A hindcast simulation (1960-2000) with an eddy resolving model. Deep Sea Res Part I Oceanogr Res Pap Hist Med Assoc 74:82-97

Vilibić I, Orlić M (2001) Least-squares tracer analysis of water masses in the South Adriatic (1967-1990). Deep Sea Res I(48):2297-2330

Vilibić I, Orlić M (2002) Adriatic water masses, their rates of formation and transport through the Otranto Strait. Deep Sea Res Part I Oceanogr Res Pap Hist Med Assoc 49(8):1321-1340
Vilibić I, Supić N (2005) Dense water generation on a shelf: the case of the Adriatic Sea. Ocean Dyn 55(5-6):403-415

Vörösmarty C, Fekete B, Tucker B (1996) Global river discharge database, RivDis. UN Educ. Sci. And Cult. Organ, Paris. http:// www.rivdis.sr.unh.edu

Wang XH, Oddo P, Pinardi N (2007) On the bottom density plume on coastal zone off Gargano (Italy) in the southern Adriatic Sea and its interannual variability. J Geophys Res 112

Wu P, Haines K (1996) Modeling the dispersal of levantine intermediate water and its role in Mediterranean deep water formation. J Geophys Res 101:6591-6607 